\title{
$\$$ Research Square

\section{Subcellular Receptor Localization in the Substantia Nigra in a Superecliptic pHlourin-Tagged D2 Receptor Knockin Mouse}

\section{Mason Trinkle}

University of Pittsburgh

Jospeph J. Lebowitz

Oregon Health \&amp; Science University Vollum Institute

Brooks Robinson

Oregon Health \&amp; Science University Vollum Institute

Judith Joyce Balcita-Pedicino

University of Pittsburgh

\section{Savas Hetelekides}

University of Pittsburgh

James R. Bunzow

Oregon Health \&amp; Science University Vollum Institute

\section{Sue Aicher}

Oregon Health \&amp; Science University

John T. Williams

Oregon Health \&amp; Science University Vollum Institute

Susan R. Sesack ( $\square$ sesack@pitt.edu )

University of Pittsburgh https://orcid.org/0000-0002-2852-7440

\section{Research Article}

Keywords: dopamine, substantia nigra, autoreceptor, D2 receptor, ultrastructure

Posted Date: April 30th, 2021

DOl: https://doi.org/10.21203/rs.3.rs-435698/v1

License: (c) (i) This work is licensed under a Creative Commons Attribution 4.0 International License. Read Full License 


\section{Abstract}

Dopamine neurons use autoregulation for appropriate modulation of goal-directed behaviors, and yet the mechanisms for D2 receptor (D2R)-mediated autoregulation are not fully understood. Electrophysiology suggests close proximity between dopamine release and receipt, but actual dendro-dendritic synapses are rare. This ultrastructural study used transgenic mice with a knockin of superecliptic green fluorescent protein (SEP) on the D2R (SEP-D2R) to determine how often autoreceptors are localized at directly apposed dendrites in the substantia nigra pars compacta (SNc). Silver-enhanced immunogold labeling for SEP-D2R was observed within dendrites, axon varicosities, astrocytes, and soma. Although most gold particles were intracellular, $28 \%$ of SEP-D2R gold was irregularly distributed along the plasma membrane. Structures immediately adjacent to dendritic membrane gold particles were axons (40\%), astrocytes $(19 \%)$, and other dendrites (7\%), with the remaining structures unidentified in single sections. Known limitations in antibody penetration suggest the actual incidence of D2R localization at apposed dendrites is probably greater than $7 \%$. Nevertheless, these results indicate that intercellular dopamine communication in the $\mathrm{SNc}$ is primarily extrasynaptic. The thin astrocytic processes often seen separating adjacent dendrites may provide channels along which transmitter diffuses to access dendritic D2Rs. Expression of D2Rs by the astrocytes themselves suggests they may participate in dopamine autoregulation. A novel finding of SEP-D2R on the axon initial segments (AISs) of SNc neurons was confirmed by immunofluorescence to involve dopamine cells. While some of this may represent axonal trafficking, membrane D2Rs might serve an autoregulatory function at the AIS yet to be physiologically characterized for dopamine neurons.

\section{Introduction}

Dopamine transmission influences various forebrain control systems, providing essential modulation of cognition, learning, and goal-directed behaviors. Disruptions in this regulation are associated with substance abuse disorder, depression, schizophrenia, and attention deficit hyperactivity disorder, among other conditions (Dunlop and Nemeroff 2007) (Grace 2016) (Kollins and Adcock 2014) (McCutcheon et al. 2019) (Solinas et al. 2018) (Volkow et al. 2017). Of the multiple dopamine pathways originating from the midbrain, the nigrostriatal tract is the largest and most extensively investigated. The degradation of this pathway in patients with Parkinson's disease reveals its critical role in the facilitation of fine motor control (Borroto-Escuela et al. 2018) (David et al. 2005) (Fahn 2015).

In order to transmit a variety of message patterns to medium spiny neurons (MSN) in the dorsal striatum, dopamine cells in the substantia nigra pars compacta (SNc) fire both tonically and in bursts (Grace and Bunney 1983a) (Lammel et al. 2008) (Steinfels et al. 1981), allowing for variable concentrations and time lengths of dopamine release. Considerable regulation of this release is required for dopamine receptors to appropriately modulate MSN responses to cortical afferents (Beaulieu and Gainetdinov 2011) (Calabresi et al. 2007) (Gardoni and Bellone 2015). Autoreceptor control is a principal mechanism for this governance, and the D2 receptor (D2R) is the only subtype mediating these effects. This is true both for somatodendritic receptors regulating firing rate within the SNc and axonal receptors providing feedback 
inhibition of dopamine synthesis and release in the striatum (Beckstead et al. 2004) (Courtney and Ford 2014) (Mercuri et al. 1997) (Morelli et al. 1988) (Wolf and Roth 1990). The fact that autoregulation is sensitive to drugs of abuse, and that addictive drugs alter afferent input and activity of SNc neurons (Beaudoin et al. 2018) (Lee et al. 1999) (Perra et al. 2011) (Sharpe et al. 2015) shows the importance of having a thorough understanding of autoreceptor localization and function.

In the SNc, dopamine neurons serve as both source and recipient of dopamine autoregulatory signals, and yet conventional dendro-dendritic synapses are found only rarely in ultrastructural studies of the midbrain (Groves and Linder 1983) (Wilson et al. 1977) (Wassaf et al. 1981) (Bayer and Pickel 1990). Hence, the exact morphological substrates for dopamine intercellular communication have been difficult to define. Electrophysiological studies analyzing the time course of evoked D2R-mediated inhibitory responses on dopamine neurons suggest a model of spatially tight dopamine release and receptor activation (Beckstead et al. 2004) (Ford et al. 2009) (Ford et al. 2010) (Courtney and Ford 2014). Additionally, the high concentration of dopamine required to elicit a D2R-dependent inhibitory response, which is around $100 \mu \mathrm{M}$, suggests that D2 autoreceptors are located close to dopamine release sites (Courtney and Ford 2014) (Ford et al. 2009).

Extensive research into somatodendritic dopamine release indicates that the mechanism is exocytotic, calcium-dependent, activity dependent, and involves a vesicle-type structure expressing the vesicular monoamine transporter type 2 (VMAT2) (Beckstead et al. 2004) (Rice and Patel 2015) (Jaffe et al. 1998) (Santiago et al. 1992) (Mendez et al. 2011) (Chen et al. 2011) (Heeringa and Abercrombie 1995) (Nirenberg et al. 1996). Nevertheless, morphological evidence of active zones beyond axodendritic and the rare dendro-dendritic synapses has not been found in the SNc. One interpretation of these observations is that autoinhibition between somatodendritic complexes of dopamine neurons involves non-canonical "synapses" that do not form junctional specializations, despite the presence of at least one active zone protein (Robinson et al. 2019). Such communication sites might still localize dendro-dendritic transmission in the sub-micron range (Courtney and Ford 2014). Potential support for this hypothesis might be obtained by identifying dendritic D2Rs localized in close proximity to other SNc dendrites. Early light and electron microscopy studies of the rat SNc and ventral tegmental area (VTA) demonstrated the presence of immunoperoxidase labeling for D2R on soma, proximal dendrites, and distal dendrites of identified dopamine neurons (Pickel et al. 2002; Sesack et al. 1994) (Yung et al. 1995). A more recent study in wildtype mice demonstrated the subcellular localization of D2Rs to the plasma membrane of VTA neurons by using a non-diffusible immunogold-silver approach (Garzón et al. 2013). Although this study did not report clustering of D2Rs on the plasma membrane near dendro-dendritic appositions, it also did not examine the SNc where the intercellular distances between dopamine neurons are shorter. Furthermore, currently available antibodies directed against the D2R may not be able to localize the receptor with high sensitivity. Hence, the hypothesis has not yet been fully tested that clustering of D2Rs near closely spaced SNc dendrites might represent sites of autoreceptor transmission within the submicron range. 
To address these concerns, we utilized a mouse line with a knockin of superecliptic green fluorescent protein (SEP) incorporated into the N-terminus of the D2R. Tagging with SEP has been shown not to alter the inhibitory functions of the D2R on SNc dopamine neurons, making it a valuable tool for fluorescence detection of autoreceptors during electrophysiological recording (Robinson et al. 2017)(see also Lebowitz et al., this volume). In a companion paper (Lebowitz et al., 2021), light microscopic examination showed frequent discrete clusters of SEP-D2R labeling along the plasma membrane of dopamine cells, sometimes in apposition to dendrites of other dopamine neurons. Here, we applied electron microscopy and immunogold-silver labeling for GFP to examine the subcellular localization of the D2R in the mouse SNc. Furthermore, for each immunogold particle indicating SEP-D2R localized to the plasma membrane, we identified the neuronal or glial structure in closest proximity to that part of the membrane, with the hypothesis that most of these would be other SNc dendrites. Finally, we also examined dendritic expression of D2Rs in the dorsolateral striatum in the same animals in order to directly compare detection sensitivity for putative autoreceptor versus postsynaptic receptor localization.

\section{Methods}

\section{Subjects and In Vivo Fixation}

All animal procedures and protocols were conducted in accordance with the National Institute of Health Guidelines for the Care and Use of Laboratory Animals. The transgenic mouse line on a C57BL/ 6 background strain had a knockin of SEP on the amino-terminus of D2Rs and was generated in the Transgenic Mouse Facility at the University of California at Irvine. The procedure for transgenic mouse generation and evidence supporting the normal functionality of SEP-tagged D2Rs has been published previously (Robinson et al. 2017). For these ultrastructural analyses, mice from the Williams laboratory were perfused by S. Aicher, and their brains were shipped to the University of Pittsburgh for examination.

SEP-D2R transgenic mice were anesthetized with $100 \mathrm{mg} / \mathrm{kg}$ sodium pentobarbital i.p. and then perfused with $5-10 \mathrm{ml}$ of saline containing 1000 units $/ \mathrm{ml}$ of heparin. The cardiovascular system was then flushed with a $0.1 \mathrm{M}$ phosphate buffer (PB; $\mathrm{pH} 7.4$ ) containing one of two fixatives: $12.5 \mathrm{ml}$ of $3.75 \%$ acrolein with $2 \%$ paraformaldehyde, followed by $50-75 \mathrm{ml}$ of $2 \%$ paraformaldehyde, or $50-75 \mathrm{ml}$ of $0.2 \%$ glutaraldehyde with $4 \%$ paraformaldehyde. Brains were extracted from the skull and post-fixed in the last fixative for 30-60 min. Brains showing optimal fixation were then stored in PB for overnight shipment to the University of Pittsburgh. Three cohorts consisting of 3, 5, and 3 brains were shipped. The first two cohorts were used for quantitation of SEP-D2R in the SNc and striatum (8 brains/animals total). The third cohort was used for dual labeling of SEP-D2R and AIS markers for electron microscopy. In addition, experimental tests to determine the ideal conditions for localizing antibodies against ankyrin- $G$ and beta IV-spectrin were conducted in 12 wildtype mice of the C57BL/ 6 strain at the University of Pittsburgh following equivalent procedures to those described above.

\section{Immunogold-silver and Immunoperoxidase Labeling}


Fixed brains were cut into blocks containing the SNc or striatum that were then sectioned at $50 \mu \mathrm{m}$ on a vibratome. Sections were treated with PB containing $1 \%$ sodium borohydride followed by rinsing with PB. Tissue was then incubated for $30 \mathrm{~min}$ in a blocking solution made in $0.1 \mathrm{M}$ tris-buffered saline (TBS; $\mathrm{pH}$ 7.6) that contained $3 \%$ normal goat serum, $1 \%$ bovine serum albumin, and $0.04 \%$ Triton-X100. Sections were then transferred to chicken anti-GFP primary antibody (Avēs Labs, Inc; GFP-1010) at a concentration of 1:500 or 1:1000 in blocking solution. According to the vendor, antibody specificity has been determined using Western blot and immunohistochemistry from transgenic mice expressing GFP. Our laboratory has also determined that brain sections from non-GFP expressing animals contain no detectable immunoreactive signal at light or electron microscopy. Tissue sections were incubated in the GFP primary antibody overnight at room temperature for $12-15$ hours, then rinsed in $0.1 \mathrm{M}$ TBS followed by $0.01 \mathrm{M}$ phosphate-buffered saline (PBS; pH 7.4).

Tissue was then rinsed with a washing buffer containing $3 \%$ normal goat serum, $0.8 \%$ bovine serum albumin, and $0.1 \%$ cold fish gelatin (Aurion). The secondary IgG antibody was $0.8 \mathrm{nM}$ gold-conjugated goat anti-chicken (Aurion). Tissue was exposed to the secondary at 1:50 in washing buffer and incubated overnight for 12-15 hours at room temperature. Excess secondary was removed by rinsing three times each in washing buffer and PBS. Tissue was then exposed to $2.5 \%$ glutaraldehyde in PBS for 10 min, followed by several rinses in PBS. Sections were then treated four times for 10 min each with Enhancement Conditioning Solution (Aurion) diluted 1:10 with ultrapure water. Sections were exposed to an RGENT-SEM proprietary silver enhancement solution (Aurion) for 120-180 min. Additional treatments in Enhancement Conditioning Solution followed at four times 10 min each, with a final rinse in $0.1 \mathrm{M} \mathrm{PB}$.

The probable detection of SEP-D2R in axon initial segments necessitated confirmation using antibodies specific for this neuronal compartment, namely beta IV-spectrin (Berghs et al. 2000) (Lacas-Gervais et al. 2004) and ankyrin-G (Hedstrom et al. 2008; Le Bras et al. 2014). An affinity purified, rabbit polyclonal antibody against beta IV-spectrin was obtained as a gift from Dr. Matthew Rasband at Baylor College of Medicine. The specificity of this antibody was previously demonstrated by preadsorption with the antigen, Western blot analysis, and complete loss of immunolabeling in mice with a knock-out of the beta IV-spectrin $\Sigma 1$ isoform (Lacas-Gervais et al. 2004) (Lysakowski et al. 2011). A mouse monoclonal antibody against ankyrin-G was purchased from the UC Davis/NIH NeuroMab Facility. Specificity was previously demonstrated by preadsorption with the peptide antigen and Western blot analysis (Le Bras et al. 2014). The two antibodies were used at concentrations from 1:50 to 1:1000 in procedures similar to those described above, except that secondary antibodies were biotinylated goat anti-mouse for ankyrin-G and goat anti-rabbit for beta IV-spectrin, both from Vector Laboratories. Tissue was incubated with secondary antibodies at 1:400 for $30 \mathrm{~min}$ and rinsed three times in TBS for $10 \mathrm{~min}$ each. Antibody-bound tissue was then exposed to a 30 min incubation in avidin-biotin peroxidase complex (ABC solution, Vector Laboratories) before being rinsed again in TBS three times for five min each. Tissue was then exposed for $3.5 \mathrm{~min}$ to a solution containing $0.022 \%$ diaminobenzidine and $0.003 \%$ hydrogen peroxide, followed by a three-step rinse in TBS for 5 min each and one rinse in PB. 
For dual labeling of both SEP-D2R and one of the AIS markers, mouse brains were fixed with acrolein and sectioned, and then the sections were incubated in a mixture of primary antibodies. From pilot testing, the best results were obtained with anti-GFP at 1:1000 and anti-beta IV-spectrin at 1:100. Immunoperoxidase processing occurred before immunogold labeling, and then silver enhancement was carried out for 60-70 $\min$.

\section{Immunofluorescence Imaging of SEP-D2R in the AIS}

All procedures were approved and performed in compliance with the appropriate guidelines set forth by the Institutional Animal Care and Use Committee at Oregon Health \& Science University. Mice were grouphoused in vented plastic cages on a 12-hour light/dark cycle with food and water available ad libitum. Male transgenic mice homozygous for the SEP-D2R knockin (21-25 days old) were used for this part of the study.

Animals were anesthetized with isoflurane and rapidly decapitated into modified Krebs buffer at $34^{\circ} \mathrm{C}$ containing (in mM): $126 \mathrm{NaCl}, 2.5 \mathrm{KCl}, 1.2 \mathrm{MgCl} 2,2.4 \mathrm{CaCl} 2,1.4 \mathrm{NaH} 2 \mathrm{PO} 4,25 \mathrm{NaHCO}$, and $11 \mathrm{D}$ Glucose. Krebs buffer used for decapitation, slicing, and slice recovery contained $10 \mu \mathrm{M}$ MK-801. Horizontal slices were cut at a thickness of $222 \mu \mathrm{m}$ using a Leica VT1000S vibratome and allowed to recover for $30 \mathrm{~min}$, both in Krebs bubbled with $95 / 5 \% \mathrm{O}_{2} / \mathrm{CO}_{2}$. To amplify the SEP-D2R signal, slices were incubated for $45 \mathrm{~min}$ in bubbled Krebs with an anti-GFP antibody (1:400) conjugated to Alexa Fluor 488 (ThermoFisher cat\#: A-21311). Excess antibody was washed with a 15 min incubation in Krebs following labeling. Fixation was achieved by incubating slices in 4\% PFA in PBS for $30 \mathrm{~min}$ at RT. Slices were blocked and permeabilized in PBS containing $0.5 \%$ fish skin gelatin (FSG) and $0.5 \%$ Tween-20 for $1 \mathrm{hr}$ at RT. Primary antibody incubation was conducted overnight at $4^{\circ} \mathrm{C}$ in PBS containing $0.1 \%$ Tween-20 and 0.5\% FSG. Anti-tyrosine hydroxylase was purchased from Sigma Aldrich (cat\#: T1299); anti-Ankyrin-G was a generous gift from Paul Jenkins (University of Michigan). Both primary antibodies were used at 1:500. Slices were washed $3 X$ for 15 min in PBS at RT before being labeled with secondary antibody at 1:500 for $1 \mathrm{hr}$ at RT in the same solution used for primary labeling. Secondaries used were anti-mouse IgG conjugated to Alexa Fluor 555 (ThermoFisher cat\# A-21422) and anti-rabbit IgG conjugated to Alexa Fluor 647 (ThermoFisher cat\# A-21245). Slices were washed 4X for 15 min in PBS before being mounted and coverslipped using Fluoromount aqueous mounting medium (Sigma-Aldrich cat\#: F4680) and nail polish to seal.

Slides were imaged on a Zeiss LSM980 with AiryScan2 using a 63X oil immersion objective. Z-stacks of labeled cells were acquired in Airyscan SR mode with a step size of $0.15 \mu \mathrm{m}$ and a pixel size of $0.14 \mu \mathrm{m}$. Airyscan2 processing was carried out in Zen Blue, and images were presented as a maximum intensity projection of the compressed z-stack.

\section{Electron Microscopy Tissue Preparation and Image Analysis}

Lipids in brain sections were fixed with $1 \%$ osmium tetroxide in $0.1 \mathrm{M} \mathrm{PB}$ for 1 hour. After rinsing in PB, tissue was exposed in five min increments to increasing concentrations of ethanol in water: $30 \%, 50 \%$, 
$70 \%$, and $95 \%$, followed by two rounds of $100 \%$ ethanol. This was followed by two five min rounds of propylene oxide incubation. Samples were then placed overnight in a 1:1 mixture of propylene oxide and epoxy resin (EM-Bed 812, Electron Microscopy Sciences) before being transferred to 100\% epoxy for 2-3 hours. Sections were then flat-embedded between two clear sheets of commercial plastic, and the resin was cured at $60^{\circ} \mathrm{C}$ for 72 hours until solid. Plasticized sections were cut to include the areas of interest, either SNc or dorsolateral striatum. These cut pieces were then glued onto blocks of solid epoxy resin. The sections were trimmed into trapezoidal shapes that contained the area of interest identified by landmarks such as blood vessels and major white matter tracts. After trimming, ultrathin sections (60 $\mathrm{nm}$ ) were cut from the resin blocks using an ultramicrotome and collected onto 400 mesh copper grids. The grid-bound tissue was then counterstained with uranyl acetate and lead citrate to enhance contrast.

Tissue was observed using a FEI Morgagni transmission electron microscope. Only one ultrathin section per grid was selected for initial analysis to avoid double counting of immunopositive profiles in serial sections. The area analyzed was near the interface between tissue and plastic resin where antibody penetration is maximal. Roughly 3,000 to $12,000 \mu \mathrm{m}^{2}$ of tissue was examined per animal, and approximately 15 micrographs were captured from each tissue section. Most micrographs contained multiple immunolabeled profiles.

The MicroBrightField Neurolucida program v.9 was used to analyze immunopositive neuronal profiles, defined as containing at least three gold particles, regardless of location, i.e. plasma membrane or intracellular. Many profiles contained more than three immunogold particles. Neurolucida was used to trace and quantify the perimeter and area of labeled profiles, while the short-axis diameter was measured manually on the micrographs with a ruler.

To compare the prevalence and density of SEP-D2R in different cellular compartments, immunopositive structures were identified based on established morphological characteristics (Peters et al. 1991). Dendrites were recognized by their larger size, smoothly contoured membranes, organelle content, and receipt of synapses; organelles consisted of mitochondria and smooth endoplasmic reticulum in the smallest dendrites, as well as rough endoplasmic reticulum and Golgi bodies in the largest. Infrequent dendritic spines in the SNc were identified by their thorny or bulbous shape and clear protrusion from dendrites. In the striatum, more numerous dendritic spines were recognized by their small size, round or cup shape, absence of mitochondria, and tendency to be postsynaptic to axon terminals. Axon varicosities were identified by their round structure and concentrations of small clear vesicles, often clustered near synapses. If axons formed a synapse, the type of synapse was recorded as either asymmetric - having parallel membranes, a widened space between membranes spanned by filaments, and a thick postsynaptic density, or symmetric - having the same features but for a thin or absent postsynaptic density (Peters et al. 1991) (Carlin et al. 1980). Astrocytes were identified by their vacuous cytoplasm and serpentine shape, often becoming markedly narrow to fill in spaces between other cellular profiles. Structures were considered unidentified if they lacked substantially distinguishing traits in single sections, which was more common with smaller profiles. 
The location of immunogold-silver particles within neuronal profiles was also determined using Neurolucida. SEP-D2Rs were considered to be associated with an organelle or the plasma membrane if the corresponding immunogold particle was within $20 \mathrm{~nm}$ of the visible structure, as determined using a $20 \mathrm{~nm}$ cursor in Neurolucida. This distance was chosen based on the approximate size of antibodies and the corresponding length of the immunogold antibody complex (Mathiisen et al. 2006). In further analysis of membrane-associated SEP-D2Rs, the neighboring cellular profile immediately apposing each gold particle was also characterized and recorded: dendrite, axon, astrocyte, or unidentified.

For each type of immunoreactive profile in each animal, the number of membrane-associated immunogold particles were totaled and used to determine an average density of immunolabeling per perimeter. Similarly, the total number of immunogold particles were summed and used to calculate the average density of immunolabeling per area. Finally, the proportion of gold particles that were associated with the plasma membrane was expressed as a percentage of the total for each profile. Regional comparisons of immunogold density and membrane distribution of immunolabeling utilized Student ttests assuming unequal variance, and reported $\mathrm{p}$ values were two-tailed. Categorical comparison of synapse type formed by immunolabeled axons between the SNc and striatum was performed using Fisher's Exact Test.

\section{Results}

\section{Cellular Localization of Immungold Labeling for SEP-D2R}

In the SNc, SEP-D2R associated immunogold was observed in soma, proximal and distal dendrites, axons, and astrocytes. Directing antibodies to the SEP tag on the D2R appeared, qualitatively, to increase overall immunoreactivity for the receptor compared to prior observations of direct immunogold labeling for D2R in the mouse midbrain (Garzón et al. 2013). Quantitative analyses focused on immunolabeled dendrites and axon terminals, with astrocyte labeling shown qualitatively and somal immunoreactivity not illustrated. From the quantitative analysis, dendrites more frequently displayed immunogold-labeling for SEP-D2R than did axon terminals: $66 \%$ versus $34 \%$ of the profiles counted in the SNc.

\section{Subcellular Distribution of SEP-D2R within SNc Dendrites}

A total of 379 SEP-D2R immunopositive dendrites were analyzed in eight animals (Table 1). The majority (72\%) of immunogold-silver particles were observed intracellularly, with fewer $(28 \%)$ on the plasma membrane (Figs. 1-5). Most intracellular immunogold particles observed in single sections were not found in association with neuronal organelles, although some appeared within or along the smooth endoplasmic reticulum or multivesicular bodies (Fig. 1). In soma (not shown) and the most proximal dendrites (Fig. 1), immunogold particles for SEP-D2R were also observed in association with the rough endoplasmic reticulum and Golgi bodies. Occasionally, immunogold particles were found in close proximity to mitochondria, even though D2Rs have no known functional relationship with these structures. 
Dendritic membrane-associated SEP-D2R gold particles were dispersed along membranes at variable distances (Fig. 1-3). As can be seen when comparing Figures 1 and 3, there was a tendency for the proportion of membrane-associated SEP-D2R immunogold to be greater in distal versus proximal dendrites (as estimated by cross-sectional diameter).

In order to assess possible D2R-mediated dendro-dendritic communication sites (distinct from traditional synapses), each membrane-associated gold particle representing SEP-D2R in the SNc was analyzed for its immediately neighboring cellular profile (Table 1 ). While $40 \%$ of membrane-associated immunogold particles were directly apposed to axon terminals (Table 1), immunogold labeling was rarely observed in or near conventional postsynaptic densities (Fig. 3). A substantial proportion of immunogold (19\%) was also found directly apposed to astrocytes (Fig. 2; Table 1). Finally, 7\% of dendritic membrane-associated SEP-D2R immunogold particles were directly apposed to other dendrites (Fig. 2; Table 1). More commonly, membrane-associated immunogold particles on dendrites were in the immediate vicinity of other dendrites but were separated from them by astrocytes and/or small axons (Fig. 2). Most gold particles representing membrane-associated SEP-D2R occurred across from profiles that could not be identified in single sections (Table 1). Had a serial section analysis been conducted, it is assumed these unidentified profiles would have sorted proportionally into the recognized categories of neighboring structures.

Dendro-dendritic synapses, reported only rarely in the ventral midbrain, were similarly encountered at low frequency in this study. Of the two synapses observed, one had dense SEP-D2R immunogold labeling associated with it (Fig. 4); the other had sparse immunoreactivity (not shown). Areas containing dendrodendritic synapses were always examined in serial sections, and for the one shown in Figure 4, we observed a continuation of dense labeling in the $z$ plane. We also paid particular attention to dendritic spines when they were encountered in the electron microscope. Even when examined in serial sections, however, they contained no more than occasional immunogold particles (Fig. 5). Also examined in serial sections were any dendrites that exhibited three or more immunogold particles clustered together at one portion of the membrane (Figs. 3a, 5). Most typically, these collections of multiple gold particles did not continue far in adjacent sections, suggesting that SEP-D2R clusters detected in the electron microscope were spatially restricted in the z-axis to roughly $60-240 \mathrm{~nm}$, i.e. one to four ultrathin sections.

Often, individual SEP-D2R immunogold particles appeared to consist of doublets or triplets (illustrated as double arrowheads in Figures 2-5). As these might signify sites of denser SEP-D2R expression than single particles, we performed a separate analysis of the apposed cellular profiles. Membrane-associated doublet or triplet particles did not, however, show any significant difference in terms of their neighboring structures, i.e. they were not more commonly apposed to other dendrites.

\section{SEP-D2R Immunogold Labeling within Axons and Astrocytes}

SEP-D2R immunoreactivity was also found in axon terminals of the SNc (Fig. 6). Similar to labeling in dendrites, immunogold particles in axon terminals were observed intracellularly (76\%) more often than on the membrane (24\%; Table 2). Only $28 \%$ of labeled axon terminals formed synapses visible in the single 
sections analyzed, the majority being of the symmetric type (Fig. 6b) versus asymmetric. The cellular profiles immediately across from SEP-D2R immunogold particles on axonal membranes were analyzed in a manner similar to those for dendrites. In this case, most gold particles were apposed to dendrites, which is expected, given that axons typically target dendrites. Other neighboring profiles were axon terminals and astrocytes, with the remainder being unidentified in single sections (Table 2). The fact that most of the gold particles on axonal membranes were found adjacent to dendrites suggests that the lower frequency with which this occurred for gold particles on dendritic membranes was not due to technical issues.

Consistent with prior reports (Bal et al. 1994) (Khan et al. 2001) (Sesack et al. 1994) (Xin et al. 2019), SEP-D2R was observed intracellularly and on the membrane of astrocytic profiles (Figs. 3, 6, 7). Labeled astrocytes were sometimes found adjoining dendrites that were also labeled for SEP-D2R (Fig. 3a, 6a).

\section{SEP-D2R Immunogold within SNc Axon Initial Segments}

During the ultrastructural analysis of SEP-D2R in the SNc, immunogold labeling was occasionally found in association with profiles $(n=9)$ showing a dense undercoating of the plasma membrane and an enlarged surrounding extracellular space that sometimes contained granules (Fig. 8). These profiles also had a diameter in the range of axon initial segments (AISs) of SNc dopamine neurons and an absence of visible synaptic inputs as reported for this compartment (Gonzalez-Cabrera et al. 2017). Such morphological features suggest that the profiles were AISs, presumably of dopamine neurons. Immunogold was observed on AIS membranes and intracellularly, associated with organelles as well as microtubules (Fig. 8a). Membrane gold on these structures sometimes occurred as doublets or triplets. We also observed several SEP-D2R gold particles roughly $40 \mathrm{~nm}$ beneath the membrane, below the dense undercoating (Fig. 8a insert). Colocalization of immunogold for SEP-D2R and immunoperoxidase staining for beta IV-spectrin verified the presence of D2Rs at the AIS (Fig. 8b). The presence of surface SEP-D2R on the AIS specifically of dopamine neurons was further examined by triple immunofluorescence confocal imaging and demonstrated by showing colocalization of SEP-D2R, TH, and ankyrin-G (Fig. 9).

\section{Subcellular Distribution of SEP-D2R within the Striatum}

The prevalence of SEP-D2R associated with the membrane of SNc dendrites seen by electron microscopy was lower than expectation, especially given the light microscopic observations from the same animals (Lebowski et al., 2021). To ensure that the ultrastructural immunocytochemical approach did not unduly limit detection of SEP-D2R, a comparison was made in the same animals to the principal target of SNc dopamine neurons, the dorsolateral striatum. In this region, D2R expression by dendrites represents a postsynaptic site known to be in higher concentration relative to the SNc (Millet et al. 2012). As in the nigra, SEP-D2R labeling in the striatum was more frequently observed in dendrites (78\% of profiles counted) than axon terminals ( $22 \%$ of profiles) (Tables 3,4 ). Similarly, both immunopositive soma and astrocytes were also seen in the striatum but were not evaluated quantitatively in this study. Many of the 
SEP-D2R immunolabeled dendrites were found to give rise to spines also showing gold particles (Fig. 10a).

SEP-D2R immunopositive dendrites in the striatum were significantly more densely labeled than dendrites in the SNc in terms of both total immunogold per area $(\mathrm{t}(12)=-4.44, \mathrm{p}=0.0008)$ and membrane gold per perimeter $(t(7)=-4.64, p=0.002$; Fig. 10A,B; Table 3). Additionally, SEP-D2R was significantly more likely to be observed associated with the dendritic membrane in the striatum than in the $\mathrm{SNc}(\mathrm{t}(11)=-7.29, \mathrm{p}<$ 0.0001) (Table 3).

SEP-D2R labeling was also observed in association with axon terminals in the striatum (Fig. 10c-e). Like dendrites, these axon terminals also were significantly more densely labeled, overall (total immunogold per area; $t(10)=-3.20, p=0.01$ ) and on the membrane (membrane gold per perimeter; $t(14)=-4.36, p=$ $0.0007)$ than those assessed in the SNc. Striatal axons labeled for SEP-D2R also contained a greater proportion of immunogold particles on the membrane than did those in the SNc $(t(9)=-6.8, p<0.0001$; Table 4). Most terminals did not form synapses in the individual plane of section (Fig. 10c,d); those that did typically formed asymmetric (Fig. 10d) more commonly than symmetric synapses (Fig. 10e). This difference in synapse type between the two brain regions was significant ( $p<0.0001$, Fishers Exact Test).

Presumed AISs were also found labeled for SEP-D2R in the striatum (data not shown) and demonstrated similar morphological features and subcellular localization of SEP-D2R as described for the SNc.

\section{Discussion}

The primary objective of this study was to provide information about the subcellular localization of the D2 receptor as it relates to an understanding of dendro-dendritic dopamine communication in the SNc. Immunohistochemistry performed on sections from SEP-D2R receptor knockin mice revealed a density of D2R labeling greater than previously observed in several electron microscopy studies. In SNc dendrites and axon terminals, some SEP-D2R immunogold was distributed along the plasma membrane, although more was observed in the interior of structures, often associated with the smooth endoplasmic reticulum. SEP-D2R immunogold particles on SNc dendritic membranes were irregularly distributed, occasionally appearing as doublets and triplets, and were infrequently localized at sites of dendro-dendritic appositions (7\%). More commonly, close SEP-D2R-labeled dendrites were separated by astrocytes and small axons, and most gold particles were directly adjacent to these structures. By comparison to the SNc, a higher expression of both total and membrane-associated SEP-D2R was observed in the dorsolateral striatum, indicating that the immunogold method used could detect higher levels of plasmalemmal SEP-D2R when present. Finally, a novel site for SEP-D2R expression was discovered on the AIS of SNc dopamine neurons, where immunogold particles were found on and near $(\sim 40 \mathrm{~nm})$ the plasma membrane. The dispersed distribution of membrane D2R labeling observed in the SNc has functional implications for understanding the nature of dopamine intercellular communication. These findings are schematically illustrated in Figure 11.

\section{Methodological Considerations}

Page 11/34 
Our examination of SEP-D2R labeling replicated much of the existing literature on the cellular and subcellular location of D2R in both the midbrain and the striatum (Garzón et al. 2013) (Hersch et al. 1995) (Pickel et al. 2002) (Sesack et al. 1994) (Wang and Pickel 2002) (Yung et al. 1995; Yung and Bolam 2000). Such consistency indicates the general soundness of the present techniques. Nevertheless, all methods have limitations that are worth considering for their influence on data interpretation.

The most significant limitation of immuno-electron microscopy is false negative outcomes due to the strong fixation of tissue proteins and minimal solubilizing of membranes necessary for preserving fine structures. Such treatment limits antibody penetration to the outer few microns of the tissue (Sesack et al. 2006). The immunogold labeling technique used to identify D2Rs also has a limited sensitivity when compared to methods like immunoperoxidase. The latter procedure results in greater signal but is unable to reveal the exact subcellular location of antigens that was the goal of this study (Sesack et al. 2006). The fact that most membrane-associated immunogold particles were observed just outside the plasma membrane is consistent with the extracellular location of the SEP tag and demonstrates the spatial fidelity of the pre-embedding approach. With indirect methods involving gold particles attached to secondary antibodies, however, a certain degree of rotational freedom (Mathiisen et al. 2006) could explain the position of other gold particles just inside the plasma membrane.

To a certain extent, the knockin approach to generate SEP-tagged D2 receptors mitigated sensitivity concerns by incorporating a foreign protein into the target of interest to serve as antigen for highly efficacious antibodies. This appeared to increase overall immunogold signal and improve quantitative assessments of receptor expression than previously available in the mouse (Garzón et al. 2013). Still, this study can only provide an estimate of D2R localization rather than ground truth, and our findings must be interpreted as an underestimation in all analyzed regions. This is especially the case given that expression of SEP-D2Rs is only about $50 \%$ of that measured in wild type animals (Robinson et al., 2017). Despite this underestimation, it is interesting that the proportion of structures found immediately adjacent to membrane gold particles representing SEP-D2R replicated estimates for neurotensin and neurotensin receptor using similar methods in the same brain region (Dana et al. 1989) (Castel et al. 1992). This observation indicates that all parts of the plasma membrane of SNc dendrites exhibited SEP-D2R labeling in the current study. As such, the ultrastructural outcomes support the light microscopic findings of frequent and relatively discrete punctate expression of SEP-D2R described in our companion paper (Lebowski et al., 2021). Seeming differences in the outcomes of the two studies most likely represent differences in sensitivity and stoichiometry of the respective labeling approaches.

Importantly, statistical comparisons between the SNc and striatum showed that significant differences in the density of D2R expression between brain regions were measurable. Specifically, the immunogold detection method for SEP-tagged receptors had the capacity to distinguish overall greater D2R concentration where it was present in the striatum. Observed differences in membrane-associated SEPD2R immunogold labeling also confirmed that the density of D2 receptors on the dendritic membranes of SNc cells is substantially lower than the expression of postsynaptic D2 receptors on striatal dendrites (Millet et al. 2012). 
Another limitation of the present electron microscopy investigation involved incomplete sampling of the SNc from the mouse brain, which mainly included the central portion along medio-lateral and rostrocaudal dimensions. While the SNc is one of the more homogenous areas of the dopamine system, differences between its sub-regions have been identified, such as between the dorsal and ventral tiers that project to different striatal regions (Björklund and Dunnett 2007) (Fallon and Loughlin 1995) (Gerfen et al. 1987) (González-Hernández and Rodríguez 2000; Gantz et al. 2018). Hence, a more exhaustive analysis might uncover subregional differences in D2R expression and function within the SNc. In lieu of more inclusive studies, the findings of the present paper should therefore be interpreted as a first approximation of the nigral area.

Finally, the present ultrastructural analyses did not verify that the D2R-expressing dendrites were from dopamine neurons, although the presence of D2R at the AIS of dopamine cells was confirmed by confocal analysis. The compact nature of the SNc as well as the high proportion of dopamine versus non-dopamine cells in this division (González-Hernández and Rodríguez 2000) (Yamaguchi et al. 2013) suggests that many of the dendrites encountered were likely to be from this phenotype, a supposition confirmed in a parallel investigation of dopamine neurons in live slices (Lebowitz et al., 2021).

\section{Intracellular D2R}

The fact that most D2R labeling in the SNc was not associated with the plasma membrane merits attention. Association with Golgi apparati, multivesicular bodies, and both forms of endoplasmic reticulum confirms previous observations (Garzón et al. 2013) (Pickel et al. 2002) (Sesack et al. 1994). D2R labeling in multivesicular bodies is probably explained by the organelle's function in membrane protein degradation (Piper and Katzmann 2007). Other intracellular D2Rs likely represent receptors being synthesized, post-translationally modified, and possibly undergoing transport. Little is known about the exact mechanisms that correctly traffic dopamine receptors from their sites of modification in the Golgi to the plasma membrane, although the process has been shown to be heavily regulated (Duvernay et al. 2005; Free et al. 2007) (Young et al. 2015). The intracellular organelle most commonly associated with D2R labeling, the smooth endoplasmic reticulum, may represent a trafficking mechanism for the receptor, given the involvement of this organelle in many cases of non-vesicular receptor transportation and storage in dendrites (Ramirez and Couve 2011). Furthermore, when D2R chaperone-assisted movement to the membrane is prevented, the result is retention of the receptor within the smooth endoplasmic reticulum (Free et al. 2007) (Prou et al. 2001). Despite the strength of this circumstantial evidence, direct proof is still needed to demonstrate that newly synthesized dopamine receptors utilize the continuous smooth endoplasmic reticulum as a corridor for traveling through neurons.

\section{Axon Initial Segment D2R}

The finding of D2R labeling at the AIS of dopamine neurons was an unexpected outcome of this investigation. Beginning with the recognition of immunolabeling within profiles having AIS features, the result was ultimately confirmed by light and electron microscopy using selective markers of the AIS and dopamine cells. Only in the AIS compartment was immunogold labeling for the D2R found $\sim 40 \mathrm{~nm}$ from 
the plasma membrane, in addition to the more typical intracellular and membrane-associated particles. The AIS features a distinctive membrane scaffolding that aids in the bundling of microtubules to facilitate vesicular transport of axonal proteins and removal of cargo that must remain in the somatodendritic complex (Leterrier 2016, 2018) (Harterink et al. 2019). Hence, the proximity of immunogold labeling to the dense membrane undercoating could indicate D2Rs that are being trafficked along microtubules through the interior of the AIS. It is unclear, however, how much sorting D2Rs require, given their presence in all major cellular compartments. Furthermore, most research investigating trafficking of dopamine receptors suggests the importance of the smooth endoplasmic reticulum (see above). Perhaps D2R labeling $\sim 40 \mathrm{~nm}$ from the AIS plasmalemma represents receptor recently removed from or awaiting rapid deployment to the membrane, although such speculation requires evidence from direct observation of D2R movement at the AIS in a functional preparation.

Although functional D2-like receptors have been described at the AIS in other brain regions (Bender et al. 2010; Bender et al. 2012) (Yang et al. 2016), our finding marks the first report that some D2R may be specifically present as an autoreceptor at the AIS of SNc dopamine neurons. The functional significance of D2Rs at this site is based on the central role of this compartment in determining neuronal firing rate (Grace and Bunney 1983b). In the SNc, the dopamine cell AIS often branches off a major dendrite (Grace and Bunney 1983b) (Gonzalez-Cabrera et al. 2017), making the AIS distinctly sensitive to the specific inputs synapsing onto the axon-bearing dendrite (Leterrier 2016) (Moubarak et al. 2019). The balance of these synaptic effects along with D2 autoreceptors will ultimately determine both firing rate and the degree to which AIS-generated action potentials back-propagate through the somatodendritic complex (Gentet and Williams 2007). Clearly, many additional studies are needed to better determine the precise contribution of the D2Rs localized to the AIS of SNc dopamine neurons.

\section{Intercellular Communication via D2R}

The present investigation was driven primarily by an interest in the mechanisms of dopamine intercellular communication. Transmission between midbrain dopamine cells is known to rarely involve dendrodendritic synapses (Bayer and Pickel 1990) (Groves and Linder 1983) (Wassaf et al. 1981) (Wilson et al. 1977), an observation corroborated in the present study. Consequently, intercellular dopamine communication via D2 receptors in the SNc and VTA occurs dominantly through non-synaptic mechanisms.

On the whole, electrophysiology studies suggest that D2 receptor activation in the SNc occurs close to sites of dendritic dopamine release and therefore probably involves a mechanism more similar to classic synaptic transmission than long-distance communication (Beckstead et al. 2004) (Ford et al. 2009) (Ford et al. 2010). Furthermore, the size of tubulovesicles storing dopamine and possibly involved in somatodendritic release (Nirenberg et al. 1996) suggests their content of substantial transmitter quantities. Although the exact sites of dendritic release cannot yet be visualized, the present finding that $7 \%$ of D2Rs occurred along dendro-dendritic appositions of SNc neurons could potentially indicate 
regions where dopamine release would be detected by autoreceptors at relatively short latency. As noted earlier, this quantitative assessment is likely an under-estimation.

The ultrastructural finding that most membrane-associated D2Rs were adjacent to axons or astrocytes suggests that many receptors bind dopamine that has diffused over distances longer than the $\sim 20 \mathrm{~nm}$ synaptic cleft (Peters et al. 1991) or $\sim 40 \mathrm{~nm}$ extracellular space (Kinney et al. 2013) (Hrabetova et al. 2018). That many of the axons in the adjacent neuropil themselves exhibit $D 2 R s$ is consistent with prior observations (Pickel et al. 2002) (Sesack et al. 1994) (Yung et al. 1995) (Garzón et al. 2013) and indicates that dopamine in the SNc can presynaptically affect release from these structures (Gantz et al. 2018). Candidates for presynaptic expression of D2Rs include the striatal complex and prefrontal cortex (Lu et al. 1998) (Koga and Momiyama 2000; Sesack 2010) (Wang and Pickel 2002) (Mengual and Pickel 2002).

Astrocytes apposed to membrane D2Rs suggest a potential barrier between diffusing dopamine and autoreceptors. Rather than always creating barriers, however, it should be considered whether astrocytes form part of specific diffusion channels, as shown for simulations of glutamate movement within the hippocampus (Kinney et al. 2013). In this case, astrocytic sheets in the SNc might facilitate D2 receptor activation by channeling dopamine and preventing its widespread diffusion and concomitant dilution. Interestingly, beta-adrenergic receptors on astrocytes directly affect neurochemical diffusion by altering the volume fraction of the extracellular space (Sherpa et al. 2016). It would be interesting to determine whether a similar function is exerted by D2Rs on midbrain astrocytes. If so, then variable regulation of diffusion by dopamine acting on astrocytic D2Rs might provide a mechanism through which different physiological or pathological states could alter dopamine intercellular communication in the SNc (Vargová and Syková 2014).

The results of the present study, interpreted in light of prior physiological investigations, suggest that D2R activation in the SNc occurs over distances that range from $40 \mathrm{~nm}$ up to several $\mu \mathrm{m}$ (Ford et al. 2009) (Hrabetova et al. 2018) (Rice and Cragg 2008). If verified, these findings may explain why measuring dopamine's actions by varied approaches sometimes yields different estimates of effective distance. Further refinement of these important issues will require determination of the exact sites where dopamine release occurs from midbrain soma and dendrites. Although the dependence of SNc dopamine release on the vesicular monoamine transporter type 2 (VMAT2) is well-established (Rice et al. 1994) (Heeringa and Abercrombie 1995) (Beckstead et al. 2004), the sites where VMAT2-bearing tubulovesicles (Nirenberg et al. 1996) participate in membrane exocytosis remain to be identified. The involvement of SNARE proteins in this process has been demonstrated (Bergquist et al. 2002) (Fortin et al. 2006) (Mendez et al. 2011) (Witkovsky et al. 2009), and most recently, the active zone protein RIM also was shown to be necessary for dendritic release of dopamine evoked by electrical stimulation (Robinson et al. 2019).

Future studies examining the subcellular localization of active zone and SNARE proteins in relationship to D2Rs will be essential for estimating the distances over which dopamine may travel to effect autoreceptor activation. Such estimates, in turn, have important implications for understanding how D2 
autoreceptors regulate dopamine cell activity in the healthy state, and how this regulation is disrupted in disease.

\section{Declarations}

\section{Funding}

National Institutes of Health Grants DA04523 (Williams) and P30 NS061800 (Aicher)

\section{Conflicts of interest/Competing interests}

None of the authors have conflicts of interest to report. The Corresponding Author acknowledges being a Co-Editor-in-Chief of this journal.

\section{Availability of data and material}

The datasets generated and/or analyzed during the current study are available from the corresponding author upon reasonable request.

\section{Code availability}

not applicable

\section{Authors' contributions}

James R. Bunzow created the superecliptic pHluorin-tagged D2 receptor knockin mouse. John T. Williams, Susan R. Sesack, and James R. Bunzow designed the studies. Mason Trinkle, Judith Joyce Balcita-Pedicino, Savas Hetelekides, Sue Aicher, and Susan R. Sesack performed and analyzed the electron microscopy studies. Joseph J. Lebowitz, Brooks Robinson, James R. Bunzow, and John T. Williams performed and analyzed the immunofluorescence imaging from live brain slices. The paper was written by Mason Trinkle, Joseph J. Lebowitz, and Susan R. Sesack with editorial contributions from Sue Aicher and John T. Williams. All authors read and approved the final manuscript.

\section{Ethics approval}

All animal procedures and protocols were conducted in accordance with the National Institute of Health Guidelines for the Care and Use of Laboratory Animals. They also complied with the appropriate guidelines set forth by the Institutional Animal Care and Use Committees at Oregon Health \& Science University and the University of Pittsburgh.

\section{Consent to participate}

not applicable 
All authors acknowledge participation in the study and development of the manuscript. All authors acknowledge reading the submitted form of this paper and consent to its submission for publication at this time.

Acknowledgements: This work was supported by National Institutes of Health Grants DA04523 (Williams) and P30 NS061800 (Aicher). The authors gratefully acknowledge the generous provision of beta IV-spectrin antibody by Dr. Matthew Rasband from the Baylor College of Medicine and the kind gift of ankyrin-G antibody from Paul Jenkins at the University of Michigan.

\section{References}

1. Bal A, Bachelot T, Savasta M, Manier M, Verna JM, Benabid AL, Feuerstein C (1994) Evidence for dopamine D2 receptor mRNA expression by striatal astrocytes in culture: in situ hybridization and polymerase chain reaction studies. Mol Brain Res 23(3):204-212

2. Bayer VE, Pickel VM (1990) Ultrastructural localization of tyrosine hydroxylase in the rat ventral tegmental area: relationship between immunolabeling density and neuronal associations. J Neurosci 10(9):2996-3013

3. Beaudoin GMJ 3rd, Gomez JA, Perkins J, Bland JL, Petko AK, Paladini CA (2018) Cocaine Selectively Reorganizes Excitatory Inputs to Substantia Nigra Pars Compacta Dopamine Neurons. J Neurosci 38(5):1151-1159. doi:10.1523/JNEUROSCI.1975-17.2017

4. Beaulieu JM, Gainetdinov RR (2011) The physiology, signaling, and pharmacology of dopamine receptors. Pharmacol Rev 63(1):182-217

5. Beckstead MJ, Grandy DK, Wickman K, Williams JT (2004) Vesicular dopamine release elicits an inhibitory postsynaptic current in midbrain dopamine neurons. Neuron 42(6):939-946. doi:10.1016/j.neuron.2004.05.019

6. Bender KJ, Ford CP, Trussell LO (2010) Dopaminergic modulation of axon initial segment calcium channels regulates action potential initiation. Neuron 68(3):500-511.

doi:10.1016/j.neuron.2010.09.026

7. Bender KJ, Uebele VN, Renger JJ, Trussell LO (2012) Control of firing patterns through modulation of axon initial segment T-type calcium channels. J Physiol 590(1):109-118.

doi:10.1113/jphysiol.2011.218768

8. Berghs S, Aggujaro D, Dirkx R Jr, Maksimova E, Stabach P, Hermel JM, Zhang JP, Philbrick W, Slepnev V, Ort T, Solimena M (2000) betalV spectrin, a new spectrin localized at axon initial segments and nodes of ranvier in the central and peripheral nervous system. J Cell Biol 151(5):985-1002. doi:10.1083/jcb.151.5.985

9. Bergquist F, Niazi HS, Nissbrandt H (2002) Evidence for different exocytosis pathways in dendritic and terminal dopamine release in vivo. Brain Res 950(1-2):245-253. doi:10.1016/s00068993(02)03047-0 
10. Björklund A, Dunnett SB (2007) Dopamine neuron systems in the brain: an update. Trends Neurosci 30(5):194-202

11. Borroto-Escuela DO, Perez De La Mora M, Manger P, Narvaez M, Beggiato S, Crespo-Ramirez M, Navarro G, Wydra K, Diaz-Cabiale Z, Rivera A, Ferraro L, Tanganelli S, Filip M, Franco R, Fuxe K (2018) Brain dopamine transmission in health and parkinson's disease: modulation of synaptic transmission and plasticity through volume transmission and dopamine heteroreceptors. Front Synaptic Neurosci 10(20):1-24. doi:10.3389/fnsyn.2018.00020

12. Calabresi P, Picconi B, Tozzi A, Di Filippo M (2007) Dopamine-mediated regulation of corticostriatal synaptic plasticity. Trends Neurosci 30(5):211-219. doi:10.1016/j.tins.2007.03.001

13. Carlin RK, Grab DJ, Cohen RS, Siekevitz P (1980) Isolation and characterization of postsynaptic densities from various brain regions: enrichment of different types of postsynaptic densities. J Cell Biol 86(3):831-845

14. Castel MN, Woulfe J, Wang X, Laduron PM, Beaudet A (1992) Light and electron microscopic localization of retrogradely transported neurotensin in rat nigrostriatal dopaminergic neurons. Neuroscience 50(2):269-282. doi:10.1016/0306-4522(92)90422-x

15. Chen BT, Patel JC, Moran KA, Rice ME (2011) Differential calcium dependence of axonal versus somatodendritic dopamine release, with characteristics of both in the ventral tegmental area. Front Syst Neurosci 5(39):1-8. doi:10.3389/fnsys.2011.00039

16. Courtney NA, Ford CP (2014) The timing of dopamine- and noradrenaline-mediated transmission reflects underlying differences in the extent of spillover and pooling. J Neurosci 34(22):7645-7656. doi:10.1523/JNEUROSCI.0166-14.2014

17. Dana C, Vial M, Leonard K, Beauregard A, Kitabgi P, Vincent JP, Rostene W, Beaudet A (1989) Electron microscopic localization of neurotensin binding sites in the midbrain tegmentum of the rat. I. Ventral tegmental area and the interfascicular nucleus. J Neurosci 9(7):2247-2257

18. David HN, Ansseau M, Abraini JH (2005) Dopamine-glutamate reciprocal modulation of release and motor responses in the rat caudate-putamen and nucleus accumbens of "intact" animals. Brain Res Rev 50(2):336-360

19. Dunlop BW, Nemeroff CB (2007) The role of dopamine in the pathophysiology of depression. Arch Gen Psychiatry 64(3):327-337

20. Duvernay MT, Filipeanu CM, Wu G (2005) The regulatory mechanisms of export trafficking of $G$ protein-coupled receptors. Cell Signal 17(12):1457-1465. doi:10.1016/j.cellsig.2005.05.020

21. Fahn S (2015) The medical treatment of Parkinson disease from James Parkinson to George Cotzias. Mov Disord 30(1):4-18. doi:10.1002/mds.26102

22. Fallon JH, Loughlin SE (1995) Substantia nigra. In: Paxinos G (ed) The Rat Nervous System, Second Edition. Academic Press, San Diego, pp 215-237

23. Ford CP, Gantz SC, Phillips PE, Williams JT (2010) Control of extracellular dopamine at dendrite and axon terminals. J Neurosci 30(20):6975-6983. doi:10.1523/JNEUROSCI.1020-10.2010 
24. Ford CP, Phillips PE, Williams JT (2009) The time course of dopamine transmission in the ventral tegmental area. J Neurosci 29(42):13344-13352. doi:10.1523/JNEUROSCI.3546-09.2009

25. Fortin GD, Desrosiers CC, Yamaguchi N, Trudeau LE (2006) Basal somatodendritic dopamine release requires snare proteins. J Neurochem 96(6):1740-1749. doi:10.1111/j.1471-4159.2006.03699.x

26. Free RB, Hazelwood LA, Cabrera DM, Spalding HN, Namkung Y, Rankin ML, Sibley DR (2007) D1 and D2 dopamine receptor expression is regulated by direct interaction with the chaperone protein calnexin. J Biol Chem 282(29):21285-21300. doi:10.1074/jbc.M701555200

27. Gantz SC, Ford CP, Morikawa H, Williams JT (2018) The evolving understanding of dopamine neurons in the substantia nigra and ventral tegmental area. Annu Rev Physiol 80:219-241. doi:10.1146/annurev-physiol-021317-121615

28. Gardoni F, Bellone C (2015) Modulation of the glutamatergic transmission by dopamine: a focus on Parkinson, Huntington and addiction diseases. Front Cell Neurosci 9(25):1-11. doi:10.3389/fncel.2015.00025

29. Garzón M, Duffy AM, Chan J, Lynch MK, Mackie K, Pickel VM (2013) Dopamine D(2) and acetylcholine alpha7 nicotinic receptors have subcellular distributions favoring mediation of convergent signaling in the mouse ventral tegmental area. Neuroscience 252:126-143. doi:10.1016/j.neuroscience.2013.08.008

30. Gentet LJ, Williams SR (2007) Dopamine gates action potential backpropagation in midbrain dopaminergic neurons. J Neurosci 27(8):1892-1901. doi:10.1523/JNEUROSCI.5234-06.2007

31. Gerfen CR, Herkenham M, Thibault J (1987) The neostriatal mosaic: II. Patch- and matrix-directed mesostriatal dopaminergic and non-dopaminergic systems. J Neurosci 7:3915-3934

32. Gonzalez-Cabrera C, Meza R, Ulloa L, Merino-Sepulveda P, Luco V, Sanhueza A, Onate-Ponce A, Bolam JP, Henny $P$ (2017) Characterization of the axon initial segment of mice substantia nigra dopaminergic neurons. J Comp Neurol 525(16):3529-3542. doi:10.1002/cne.24288

33. González-Hernández T, Rodríguez M (2000) Compartmental organization and chemical profile of dopaminergic and GABAergic neurons in the substantia nigra of the rat. J Comp Neurol 421:107135

34. Grace AA (2016) Dysregulation of the dopamine system in the pathophysiology of schizophrenia and depression. Nat Rev Neurosci 17(8):524-532. doi:10.1038/nrn.2016.57

35. Grace AA, Bunney BS (1983a) Intracellular and extracellular electrophysiology of nigral dopaminergic neurons. 1. Identification and characterization. Neuroscience 10:301-315

36. Grace AA, Bunney BS (1983b) Intracellular and extracellular electrophysiology of nigral dopaminergic neurons. 2. Action potential generating mechanisms and morphological correlates. Neuroscience 10:317-331

37. Groves PM, Linder JC (1983) Dendro-dendritic synapses in substantia nigra: descriptions based on analysis of serial sections. Exp Brain Res 49:209-217

38. Harterink M, Vocking K, Pan X, Soriano Jerez EM, Slenders L, Freal A, Tas RP, van de Wetering WJ, Timmer K, Motshagen J, van Beuningen SFB, Kapitein LC, Geerts WJC, Post JA, Hoogenraad CC 
(2019) TRIM46 organizes microtubule fasciculation in the axon initial segment. J Neurosci 39(25):4864-4873. doi:10.1523/JNEUROSCI.3105-18.2019

39. Hedstrom KL, Ogawa Y, Rasband MN (2008) AnkyrinG is required for maintenance of the axon initial segment and neuronal polarity. J Cell Biol 183(4):635-640. doi:10.1083/jcb.200806112

40. Heeringa MJ, Abercrombie ED (1995) Biochemistry of somatodendritic dopamine release in substantia nigra: an in vivo comparison with striatal dopamine release. J Neurochem 65:192-200

41. Hersch SM, Ciliax BJ, Gutekunst CA, Rees HD, Heilman CJ, Yung KKL, Bolam JP, Ince E, Yi H, Levey Al (1995) Electron microscopic analysis of D1 and D2 dopamine receptor proteins in the dorsal striatum and their synaptic relationships with motor corticostriatal afferents. J Neurosci 15(7 Pt 2):52225237

42. Hrabetova S, Cognet L, Rusakov DA, Nagerl UV (2018) Unveiling the extracellular space of the brain: From super-resolved microstructure to in vivo function. J Neurosci 38(44):9355-9363. doi:10.1523/JNEUROSCI.1664-18.2018

43. Jaffe EH, Marty A, Schulte A, Chow RH (1998) Extrasynaptic vesicular transmitter release from the somata of substantia nigra neurons in rat midbrain slices. J Neurosci 18(10):3548-3553

44. Khan ZU, Koulen P, Rubinstein M, Grandy DK, Goldman-Rakic PS (2001) An astroglia-linked dopamine D2-receptor action in prefrontal cortex. Proceedings of the National Academy of Sciences 98 (4):1964-1969

45. Kinney JP, Spacek J, Bartol TM, Bajaj CL, Harris KM, Sejnowski TJ (2013) Extracellular sheets and tunnels modulate glutamate diffusion in hippocampal neuropil. J Comp Neurol 521(2):448-464. doi:10.1002/cne.23181

46. Koga E, Momiyama T (2000) Presynaptic dopamine D2-like receptors inhibit excitatory transmission onto rat ventral tegmental dopaminergic neurones. J Physiol 523 Pt 1:163-173

47. Kollins SH, Adcock RA (2014) ADHD, altered dopamine neurotransmission, and disrupted reinforcement processes: implications for smoking and nicotine dependence. Prog Neuropsychopharmacol Biol Psychiatry 52:70-78. doi:10.1016/j.pnpbp.2014.02.002

48. Lacas-Gervais S, Guo J, Strenzke N, Scarfone E, Kolpe M, Jahkel M, De Camilli P, Moser T, Rasband MN, Solimena M (2004) BetalVSigma1 spectrin stabilizes the nodes of Ranvier and axon initial segments. J Cell Biol 166(7):983-990. doi:10.1083/jcb.200408007

49. Lammel S, Hetzel A, Hackel O, Jones I, Liss B, Roeper J (2008) Unique properties of mesoprefrontal neurons within a dual mesocorticolimbic dopamine system. Neuron 57:760-773

50. Le Bras B, Freal A, Czarnecki A, Legendre P, Bullier E, Komada M, Brophy PJ, Davenne M, Couraud F (2014) In vivo assembly of the axon initial segment in motor neurons. Brain Struct Funct 219(4):1433-1450. doi:10.1007/s00429-013-0578-7

51. Lee TH, Gao WY, Davidson C, Ellinwood EH (1999) Altered activity of midbrain dopamine neurons following 7-day withdrawal from chronic cocaine abuse is normalized by D2 receptor stimulation during the early withdrawal phase. Neuropsychopharmacology 21(1):127-136. doi:10.1016/S0893133X(99)00011-1 
52. Leterrier $C$ (2016) The axon initial segment, 50 years later: A nexus for neuronal organization and function. Curr Top Membr 77:185-233. doi:10.1016/bs.ctm.2015.10.005

53. Leterrier $C$ (2018) The axon initial segment: An updated viewpoint. J Neurosci 38(9):2135-2145. doi:10.1523/JNEUROSCI.1922-17.2018

54. Lu X-Y, Ghasemzadeh MB, Kalivas PW (1998) Expression of D1 receptor, D2 receptor, substance P and enkephalin messenger RNAs in the neurons projecting from the nucleus accumbens. Neuroscience 82:767-780

55. Lysakowski A, Gaboyard-Niay S, Calin-Jageman I, Chatlani S, Price SD, Eatock RA (2011) Molecular microdomains in a sensory terminal, the vestibular calyx ending. J Neurosci 31(27):10101-10114. doi:10.1523/JNEUROSCI.0521-11.2011

56. Mathiisen TM, Nagelhus EA, Jouleh B, Torp R, Frydenlund DS, Mylonakou M-N, Amiry-Moghaddam M, Covolan L, Utvik JK, Riber B, Gujord KM, Knutsen J, Skare Ø, Laake P, Davanger S, Haug F-M, Rinvik E, Ottersen OP (2006) Postembedding immunogold cytochemistry of membrane molecules and amino acid transmitters in the central nervous system. In: Zaborszky L, Wouterlood FG, Lanciego JL (eds) Neuroanatomical Tract-Tracing 3: Molecules, Neurons, Systems. Springer, New York, pp 72108

57. McCutcheon RA, Abi-Dargham A, Howes OD (2019) Schizophrenia, dopamine and the striatum: From biology to symptoms. Trends Neurosci 42(3):205-220. doi:10.1016/j.tins.2018.12.004

58. Mendez JA, Bourque MJ, Fasano C, Kortleven C, Trudeau LE (2011) Somatodendritic dopamine release requires synaptotagmin 4 and 7 and the participation of voltage-gated calcium channels. $J$ Biol Chem 286(27):23928-23937. doi:10.1074/jbc.M111.218032

59. Mengual E, Pickel VM (2002) Ultrastructural immunocytochemical localization of the dopamine D2 receptor and tyrosine hydroxylase in the rat ventral pallidum. Synapse 43(3):151-162

60. Mercuri NB, Saiardi A, Bonci A, Picetti R, Calabresi P, Bernardi G, Borrelli E (1997) Loss of autoreceptor function in dopaminergic neurons from dopamine D2 receptor deficient mice. Neuroscience 79(2):323-327

61. Millet P, Moulin-Sallanon M, Tournier BB, Dumas N, Charnay Y, Ibanez V, Ginovart N (2012) Quantification of dopamine $D(2 / 3)$ receptors in rat brain using factor analysis corrected [18F]Fallypride images. Neuroimage 62(3):1455-1468. doi:10.1016/j.neuroimage.2012.05.075

62. Morelli M, Mennini T, Di Chiara G (1988) Nigral dopamine autoreceptors are exclusively of the D2 type: quantitative autoradiography of [125I]iodosulpride and [125I]SCH 23982 in adjacent brain sections. Neuroscience 27(3):865-870

63. Moubarak E, Engel D, Dufour MA, Tapia M, Tell F, Goaillard JM (2019) Robustness to axon initial segment variation is explained by somatodendritic excitability in rat substantia nigra dopaminergic neurons. J Neurosci 39(26):5044-5063. doi:10.1523/JNEUROSCI.2781-18.2019

64. Nirenberg MJ, Chan J, Liu Y, Edwards RH, Pickel VM (1996) Ultrastructural localization of the vesicular monoamine transporter-2 in midbrain dopaminergic neurons: potential sites for somatodendritic storage and release of dopamine. J Neurosci 16:4135-4145 
65. Perra S, Clements MA, Bernier BE, Morikawa H (2011) In vivo ethanol experience increases $D(2)$ autoinhibition in the ventral tegmental area. Neuropsychopharmacology 36(5):993-1002. doi:10.1038/npp.2010.237

66. Peters A, Palay SL, Webster HF (1991) The Fine Structure of the Nervous System. Neurons and Their Supporting Cells, 3rd edn. Oxford University Press, New York

67. Pickel VM, Chan J, Nirenberg MJ (2002) Region-specific targeting of dopamine D2-receptors and somatodendritic vesicular monoamine transporter 2 (VMAT2) within ventral tegmental area subdivisions. Synapse 45(2):113-124

68. Piper RC, Katzmann DJ (2007) Biogenesis and function of multivesicular bodies. Annu Rev Cell Dev Biol 23:519-547. doi:10.1146/annurev.cellbio.23.090506.123319

69. Prou D, Gu WJ, Le Crom S, Vincent JD, Salamero J, Vernier P (2001) Intracellular retention of the two isoforms of the $\mathrm{D}(2)$ dopamine receptor promotes endoplasmic reticulum disruption. J Cell Sci 114(Pt 19):3517-3527

70. Ramirez OA, Couve A (2011) The endoplasmic reticulum and protein trafficking in dendrites and axons. Trends Cell Biol 21(4):219-227. doi:10.1016/j.tcb.2010.12.003

71. Rice ME, Cragg SJ (2008) Dopamine spillover after quantal release: rethinking dopamine transmission in the nigrostriatal pathway. Brain Res Rev 58(2):303-313

72. Rice ME, Patel JC (2015) Somatodendritic dopamine release: recent mechanistic insights. Philos Trans R Soc Lond B Biol Sci 370(1672):1-14. doi:10.1098/rstb.2014.0185

73. Rice ME, Richards CD, Nedergaard S, Hounsgaard J, Nicholson C, Greenfield SA (1994) Direct monitoring of dopamine and 5-HT release in substantia nigra and ventral tegmental area in vitro. Exp Brain Res 100(3):395-406. doi:10.1007/bf02738400

74. Robinson BG, Bunzow JR, Grimm JB, Lavis LD, Dudman JT, Brown J, Neve KA, Williams JT (2017) Desensitized D2 autoreceptors are resistant to trafficking. Sci Rep 7(4379):1-14. doi:10.1038/s41598-017-04728-z

75. Robinson BG, Cai X, Wang J, Bunzow JR, Williams JT, Kaeser PS (2019) RIM is essential for stimulated but not spontaneous somatodendritic dopamine release in the midbrain. Elife 8. doi:10.7554/eLife.47972

76. Santiago M, Machado A, Cano J (1992) Fast sodium channel dependency of the somatodendritic release of dopamine in the rat's brain. Neurosci Lett 148(1-2):145-147. doi:10.1016/03043940(92)90825-r

77. Sesack SR (2010) Functional implications of dopamine D2 receptor localization in relation to glutamate neurons. In: Iversen LL, Iversen SD, Dunnett SB, Bjorklund A (eds) Dopamine Handbook. Oxford University Press, New York, pp 22-37

78. Sesack SR, Aoki C, Pickel VM (1994) Ultrastructural localization of D2 receptor-like immunoreactivity in midbrain dopamine neurons and their striatal targets. J Neurosci 14(1):88-106

79. Sesack SR, Miner LAH, Omelchenko N (2006) Pre-embedding immunoelectron microscopy: applications for studies of the nervous system. In: Zaborszky L, Wouterlood FG, Lanciego JL (eds) 
Neuroanatomical Tract-Tracing 3: Molecules, Neurons, Systems. Springer, New York, pp 6-71

80. Sharpe AL, Varela E, Bettinger L, Beckstead MJ (2015) Methamphetamine self-administration in mice decreases GIRK channel-mediated currents in midbrain dopamine neurons. Int J Neuropsychopharmacol 18(5):1-10. doi:10.1093/ijnp/pyu073

81. Sherpa AD, Xiao F, Joseph N, Aoki C, Hrabetova S (2016) Activation of beta-adrenergic receptors in rat visual cortex expands astrocytic processes and reduces extracellular space volume. Synapse 70(8):307-316. doi:10.1002/syn.21908

82. Solinas M, Belujon P, Fernagut PO, Jaber M, Thiriet N (2018) Dopamine and addiction: what have we learned from 40 years of research. J Neural Transm 126:481-516. doi:10.1007/s00702-018-1957-2

83. Steinfels GF, Heym J, Jacobs BL (1981) Single unit activity of dopaminergic neurons in freely moving cuts. Life Sci 29(14):1435-1442

84. Vargová L, Syková E (2014) Astrocytes and extracellular matrix in extrasynaptic volume transmission. Philos Trans R Soc Lond B Biol Sci 369(1654):20130608. doi:10.1098/rstb.2013.0608

85. Volkow ND, Wise RA, Baler R (2017) The dopamine motive system: implications for drug and food addiction. Nat Rev Neurosci 18(12):741-752. doi:10.1038/nrn.2017.130

86. Wang H, Pickel VM (2002) Dopamine D2 receptors are present in prefrontal cortical afferents and their targets in patches of the rat caudate-putamen nucleus. J Comp Neurol 442(4):392-404

87. Wassaf M, Berod A, Sotelo C (1981) Dopaminergic dendrites in the pars reticulata of the rat substantia nigra and their striatal input. Combined immunocytochemical localization of tyrosine hydroxylases and anterograde degeneration. Neuroscience 6:2125-2139

88. Wilson CJ, Groves PM, Fifkova E (1977) Monoaminergic synapses, including dendro-dendritic synapses in the rat substantia nigra. Exp Brain Res 30(2-3):161-174

89. Witkovsky P, Patel JC, Lee CR, Rice ME (2009) Immunocytochemical identification of proteins involved in dopamine release from the somatodendritic compartment of nigral dopaminergic neurons. Neuroscience 164(2):488-496. doi:10.1016/j.neuroscience.2009.08.017

90. Wolf ME, Roth RH (1990) Autoreceptor regulation of dopamine synthesis. Ann N Y Acad Sci 604:323-343

91. Xin W, Schuebel KE, Jair KW, Cimbro R, De Biase LM, Goldman D, Bonci A (2019) Ventral midbrain astrocytes display unique physiological features and sensitivity to dopamine D2 receptor signaling. Neuropsychopharmacology 44(2):344-355. doi:10.1038/s41386-018-0151-4

92. Yamaguchi T, Wang HL, Morales M (2013) Glutamate neurons in the substantia nigra compacta and retrorubral field. Eur J Neurosci 38(11):3602-3610. doi:10.1111/ejn.12359

93. Yang S, Ben-Shalom R, Ahn M, Liptak AT, van Rijn RM, Whistler JL, Bender KJ (2016) $\beta$-arrestindependent dopaminergic regulation of calcium channel activity in the axon initial segment. Cell Rep 16(6):1518-1526. doi:10.1016/j.celrep.2016.06.098

94. Young B, Wertman J, Dupre DJ (2015) Regulation of GPCR anterograde trafficking by molecular chaperones and motifs. Prog Mol Biol Transl Sci 132:289-305. doi:10.1016/bs.pmbts.2015.02.012 
95. Yung KK, Bolam JP (2000) Localization of dopamine D1 and D2 receptors in the rat neostriatum: synaptic interaction with glutamate- and GABA-containing axonal terminals. Synapse 38(4):413-420

96. Yung KK, Bolam JP, Smith AD, Hersch SM, Ciliax BJ, Levey Al (1995) Immunocytochemical localization of D1 and D2 dopamine receptors in the basal ganglia of the rat: light and electron microscopy. Neuroscience 65(3):709-730

\section{Tables}

Due to technical limitations, tables are only available as a download in the Supplemental Files section.

\section{Figures}

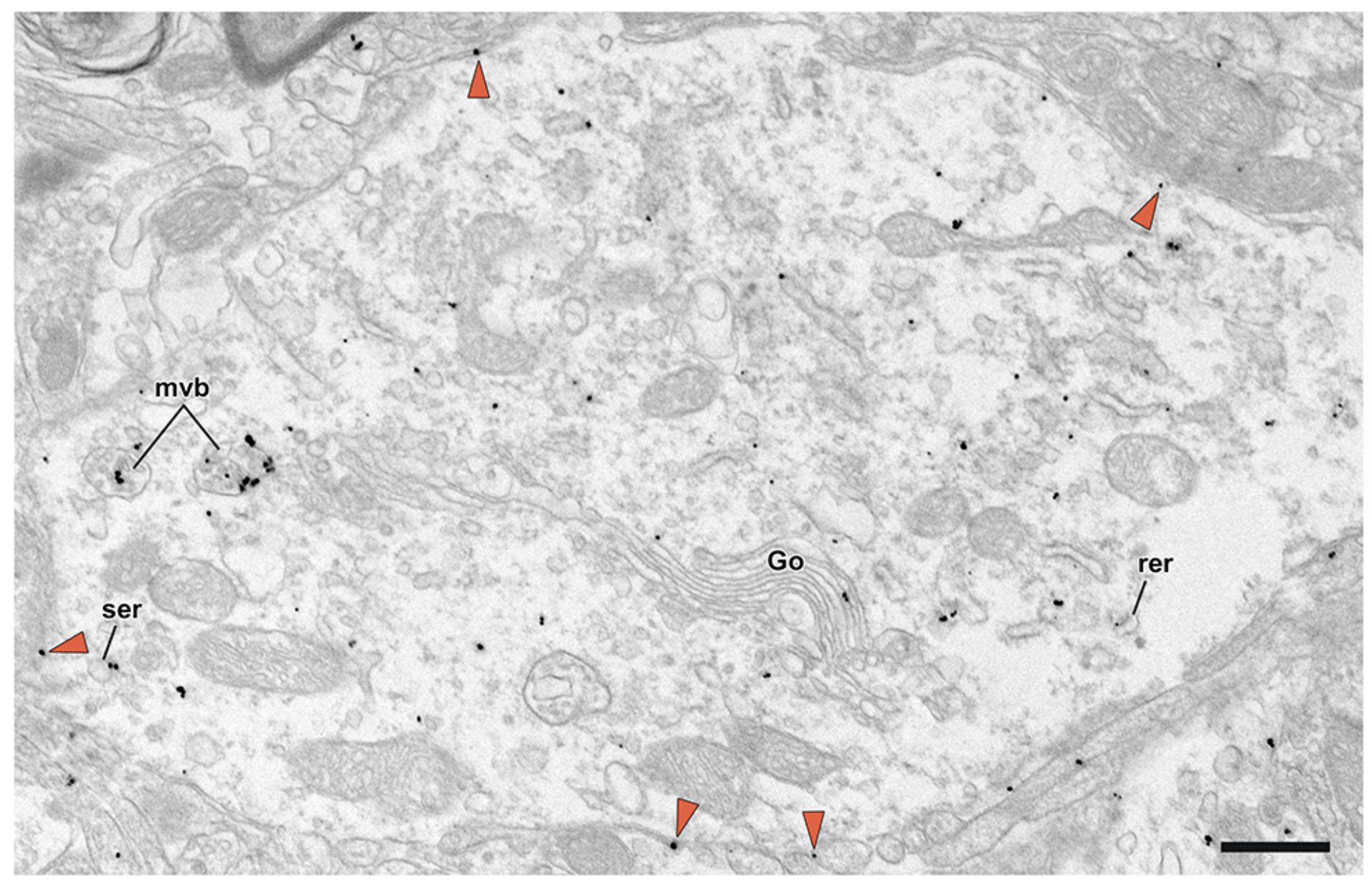

\section{Figure 1}

Electron micrograph of a SEP-D2R immunogold-labeled proximal dendrite in the SNc. Immunogold labeling is mainly intracellular and less frequently spread diffusely along the plasma membrane (orange arrowheads). Intracellular immunogold particles are associated with rough endoplasmic reticulum (rer), smooth endoplasmic reticulum (ser), Golgi apparatus (Go), and multivesicular bodies (mvb). Scale bar $0.6 \mu \mathrm{m}$ 


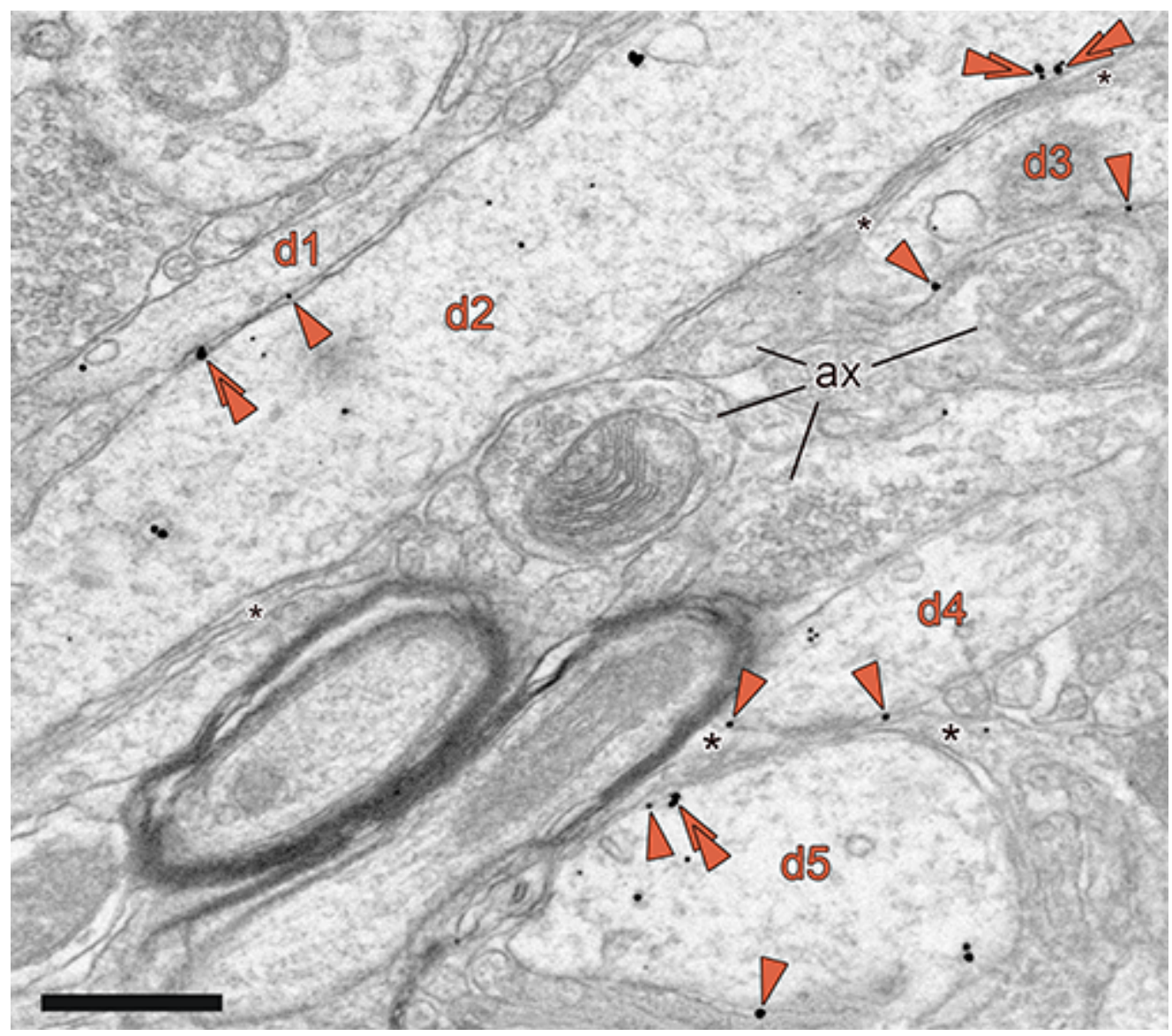

Figure 2

Electron micrograph of SEP-D2R immunogold-labeled dendrites (d1-d5) in apposition or separated by axons and astrocytes in the SNc. The $\mathrm{d} 1$ and $\mathrm{d} 2$ dendrites share a direct apposition of their membranes, while the remaining dendrites are separated from each other by astrocytic leaflets (asterisks between $\mathrm{d} 2$ and d3, d4 and d5) or axons (ax) in the adjacent neuropil. Membrane SEP-D2R gold is indicated by orange arrowheads; double arrowheads indicate gold particles consisting of doublets. Scale bar $0.6 \mu \mathrm{m}$ 

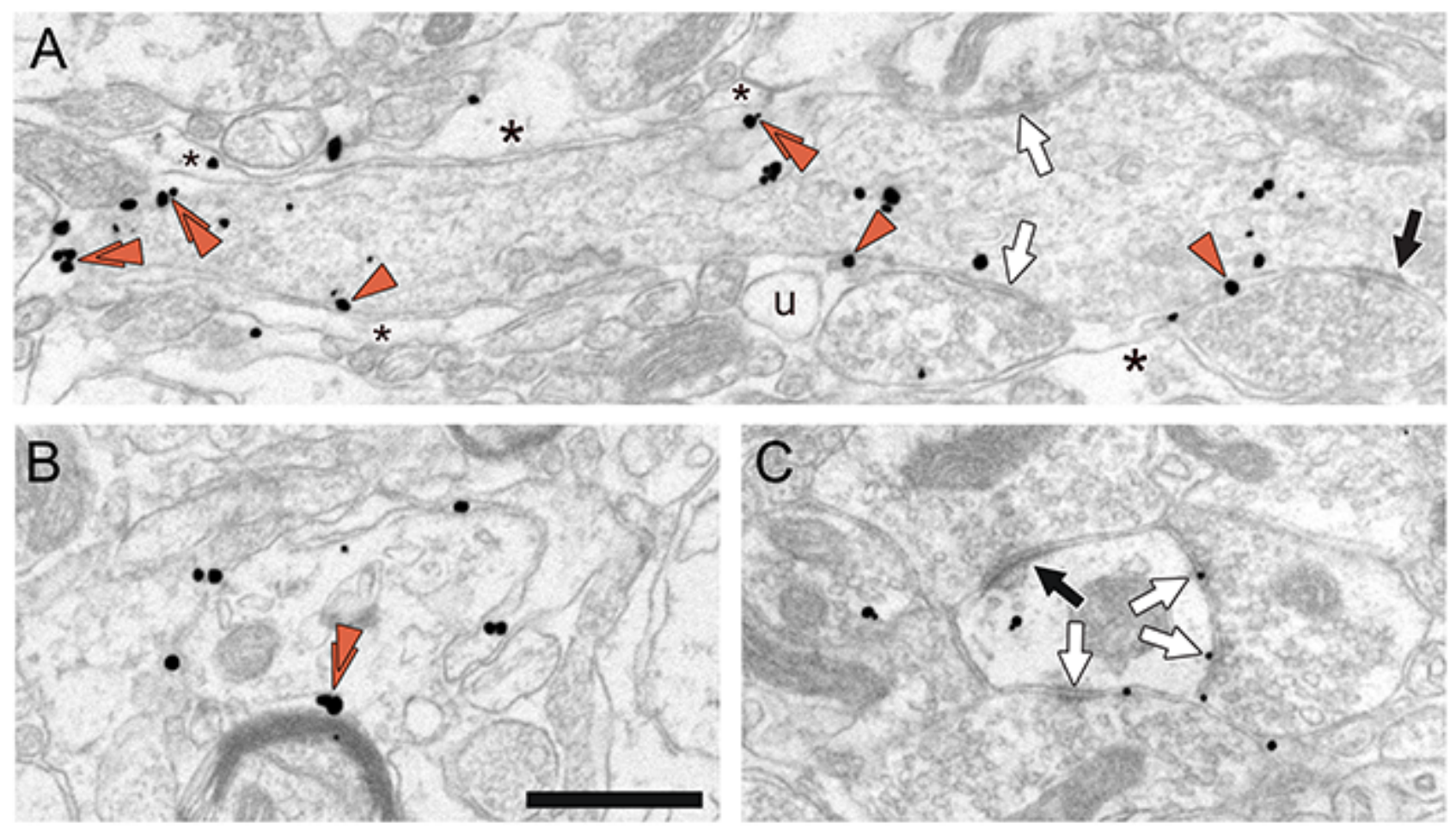

Figure 3

Electron micrographs of SEP-D2R immunogold-labeled distal dendrites in the SNc. (a) SEP-D2R immunogold is commonly associated with the cell membrane (orange arrowheads; double arrowheads show doublet or triplet particles), where it is randomly dispersed and typically adjacent to axons and astrocytes (asterisks) or unidentified profiles (u). The dense membrane accumulation of gold particles at the left of this dendrite did not recur when examined in serial sections. The dendrite receives symmetric synapses (white arrows) and asymmetric synapses (black arrow) from unlabeled axon terminals. (b) An atypical immuno-positive distal dendrite contains only membrane-associated SEP-D2R (single arrowheads omitted). (c) Along with multiple symmetric synapses, this labeled dendrite receives an asymmetric synapse from an axon terminal. Atypically, the membrane-associated immunogold particles at the right occur in or near the synaptic junctions. Scale bar $0.6 \mu \mathrm{m}$ 

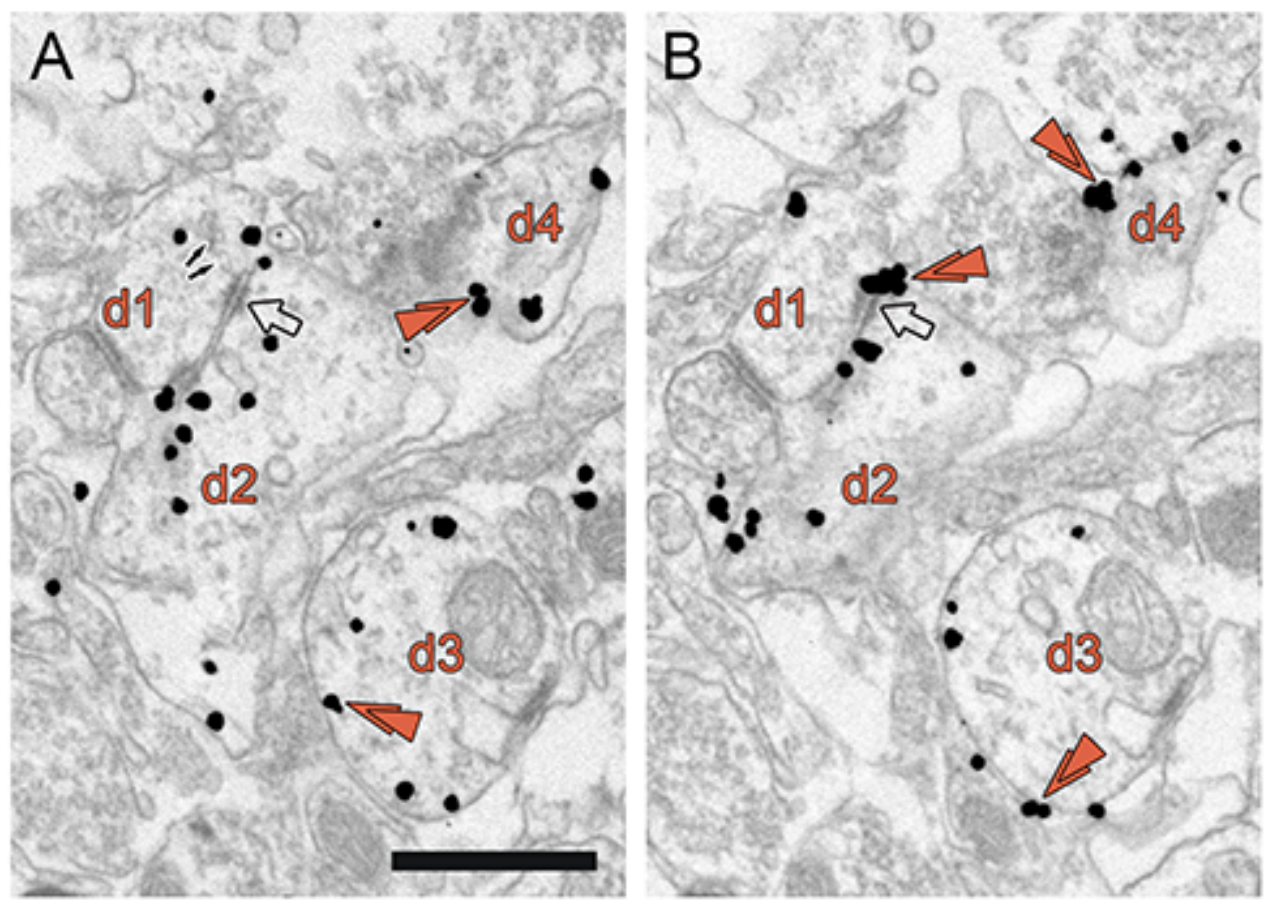

\section{Figure 4}

Serial electron micrographs of SEP-D2R immunogold-labeled distal dendrites (d1-d4) in the SNc. Membrane-associated doublet or triplet gold particles are shown by double arrowheads. A rare dendrodendritic synapse (transparent arrow) is visible between dendrites $\mathrm{d} 1 \mathrm{~d}$ and $\mathrm{d} 2$. The small arrows in panel a indicate a few vesicles in close proximity to this site. Membrane-associated SEP-D2R is found adjacent to this synapse, especially as depicted in panel b. Dendrites $\mathrm{d} 3$ and $\mathrm{d} 4 \mathrm{show}$ preferential membrane-associated SEP-D2R. Scale bar $0.6 \mu \mathrm{m}$ 


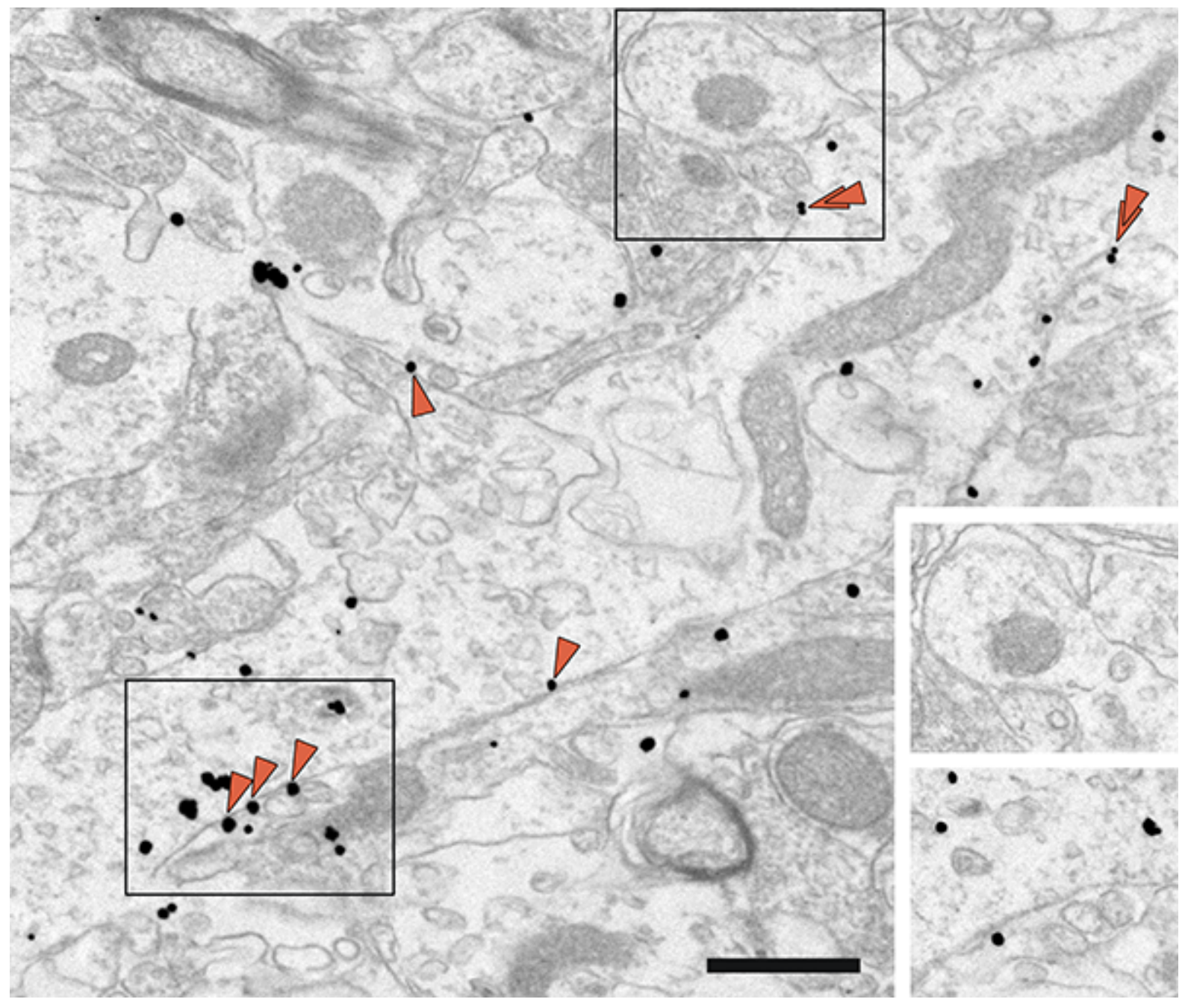

Figure 5

Electron micrograph of a SEP-D2R immunogold-labeled dendrite in the SNc. In addition to individual gold particles associated with the plasma membrane (orange arrowheads; double arrowheads show doublet or triplet particles), a grouping of membrane gold is found in one specific location (lower black boxed area). Serial sections through the relevant membrane region indicate that the SEP-D2R cluster does not continue far into the z-plane (lower insert). This dendrite also gives rise to a spine (upper black boxed area) that contains an immunogold particle within the neck. Analysis of serial sections suggests this spine is otherwise unlabeled for SEP-D2R (upper insert). Scale bar $0.6 \mu \mathrm{m}$ 

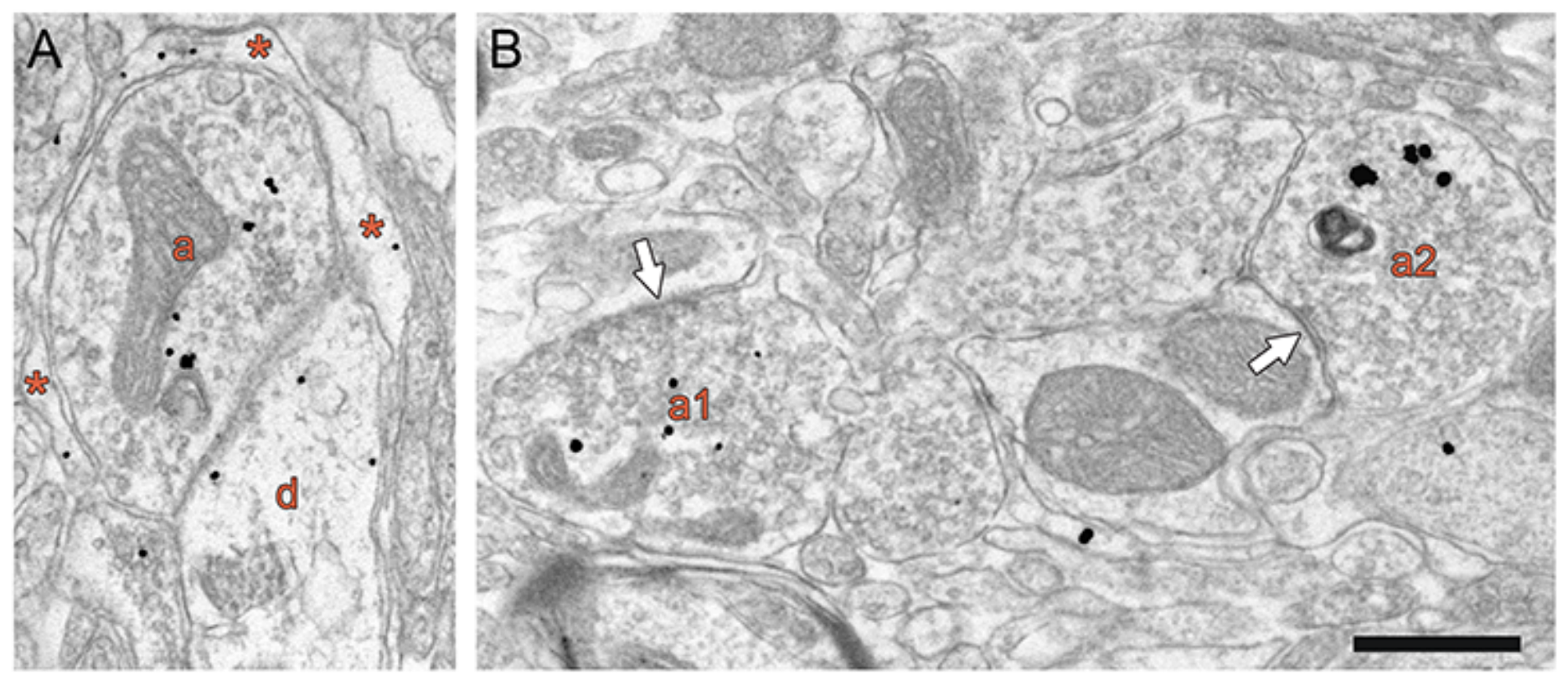

\section{Figure 6}

Electron micrographs of the SNc showing immunogold-silver labeling for SEP-D2R in representative axon varicosities (a). As was typical, most immunogold-silver particles are contained within the intracellular environment rather than being found on the plasmalemma. Often immunoreactive axons do not form synaptic contacts in single sections, although the labeled axon in panel a is closely apposed to a labeled dendrite (d) and is surrounded by an immunoreactive astrocyte (orange asterisks). When synapses are formed by immunolabeled axons ( $\mathrm{a} 1$ and $\mathrm{a} 2$ in panel $\mathrm{b}$ ), they are most commonly symmetric (white arrows) and onto immunonegative dendrites. Scale bar $0.6 \mu \mathrm{m}$
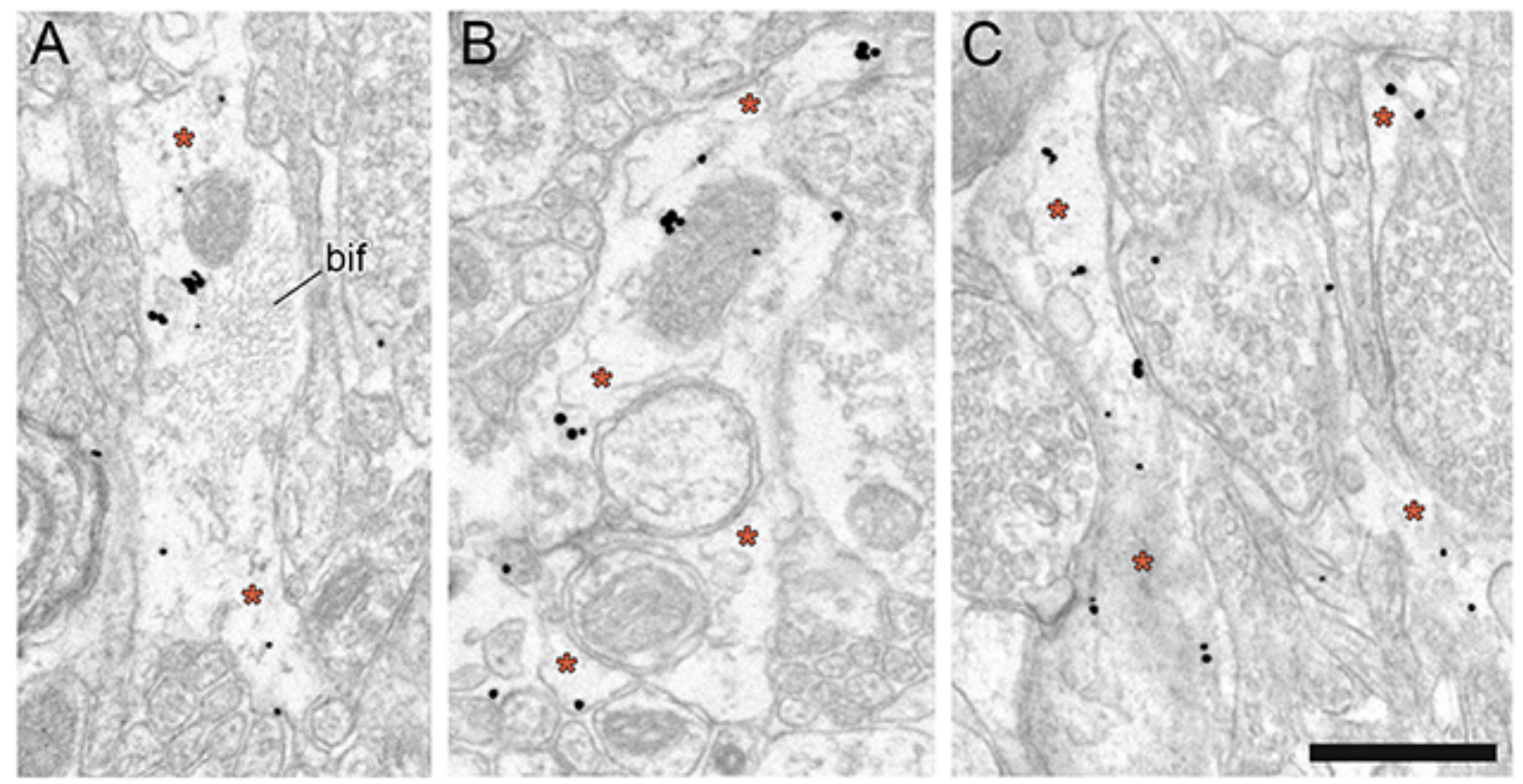

\section{Figure 7}


Electron micrographs of the SNc from SEP-D2R transgenic mice showing immunogold-silver labeling in glial profiles (orange asterisks). These are likely astrocytes as evidenced by their electron lucent cytoplasm, convoluted shape, and presence of bundles of intermediate filaments (bif). Scale bar $0.6 \mu \mathrm{m}$
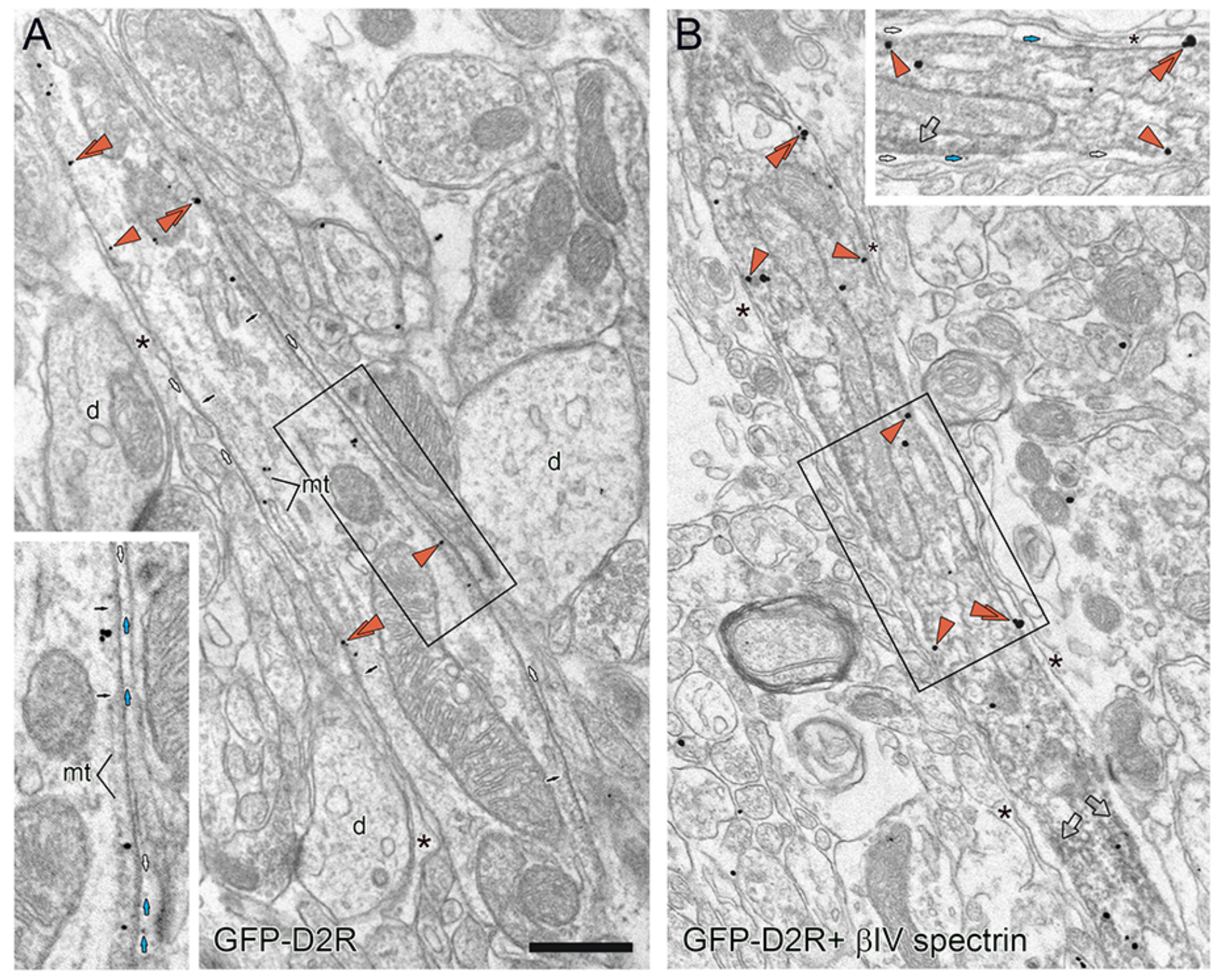

\section{Figure 8}

SEP-D2R labeling of putative axon initial segments in the mouse SNc. a,b. Electron micrographic images showing immunogold-silver labeling for SEP-D2R in structures with morphological features indicative of the AIS: dense undercoating of the plasma membrane (small black arrows in panel a), apparent microtubules ( $\mathrm{mt}$ in panel a) near the membrane, and enlargements of the extracellular space (small white arrows in panels $a, b$ ) sometimes containing granules (small blue arrows in panels $a, b)$. Unlabeled astrocytes $\left(^{\star}\right)$ appear in proximity. In panel b, the immunoreactive structure is verified as an AIS by immunoperoxidase labeling for beta IV-spectrin; transparent arrowheads indicate accumulations of peroxidase product near the plasma membrane that obscure the dense undercoating and microtubules. Orange arrowheads in panels $a$ and $b$ indicate gold particles for SEP-D2R that are close to the plasma 
membrane; double arrowheads show doublet or triplet particles. The boxed region in panel a, shown at higher magnification and contrast in the insert, demonstrates that some gold particles are displaced from the plasma membrane by roughly $40 \mathrm{~nm}$ and may be associated with microtubules. The boxed region in panal b, shown at higher magnification and contrast in the insert, shows that some gold particles are more immediately adjacent to the membrane and even just outside the plasmalemma. Scale bar $0.6 \mu m$ for panels $a$ and b, $0.38 \mu \mathrm{m}$ for panel $\mathrm{a}$ insert, $0.47 \mu \mathrm{m}$ for panel $\mathrm{b}$ insert

A.

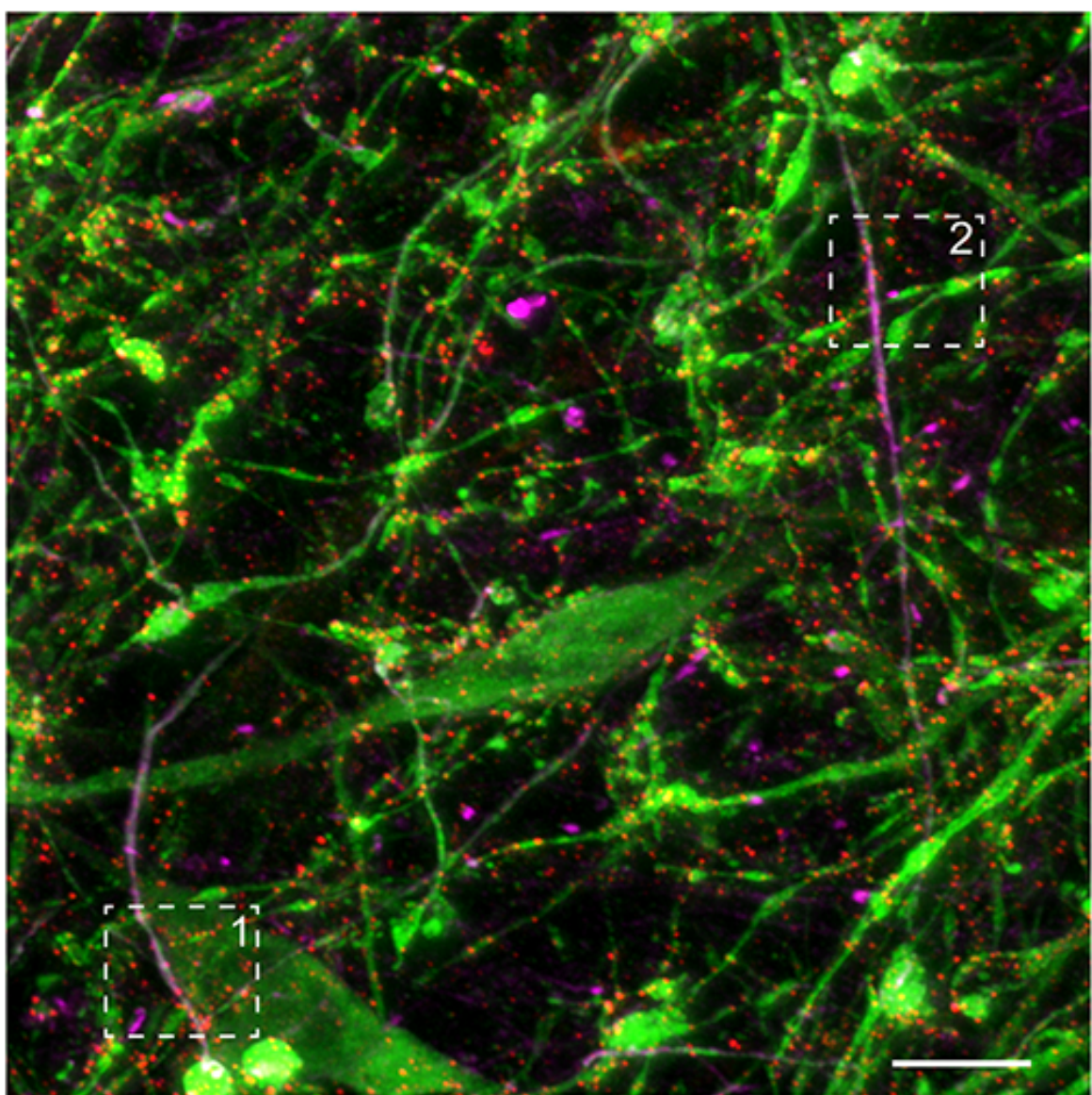

B.
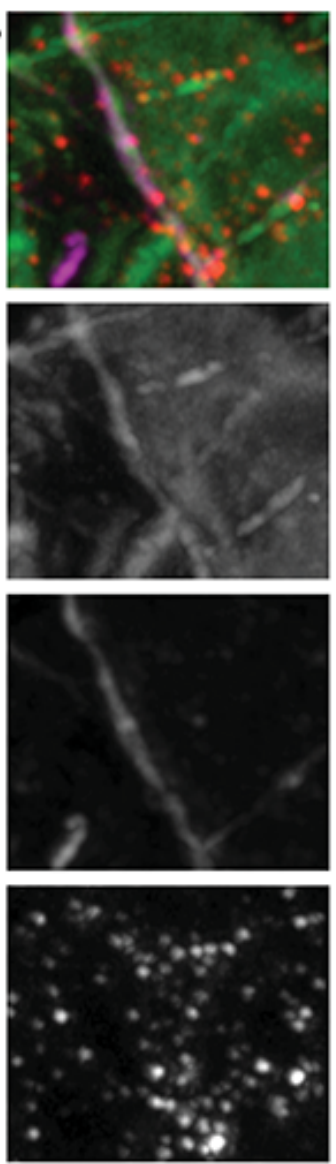

C.

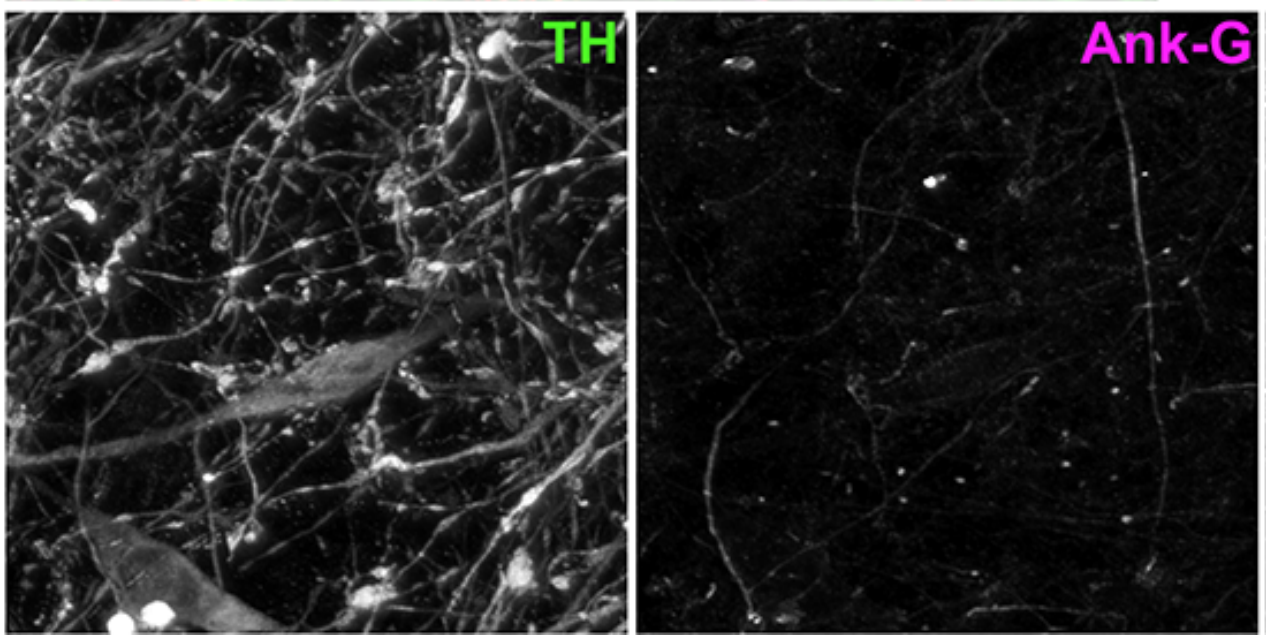

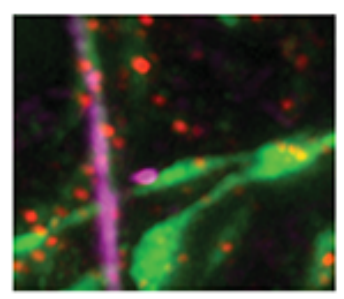

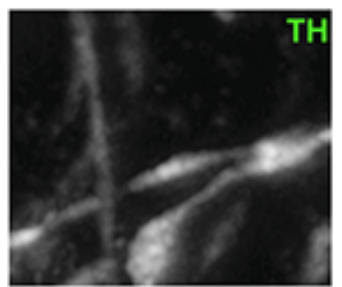

Ank-G
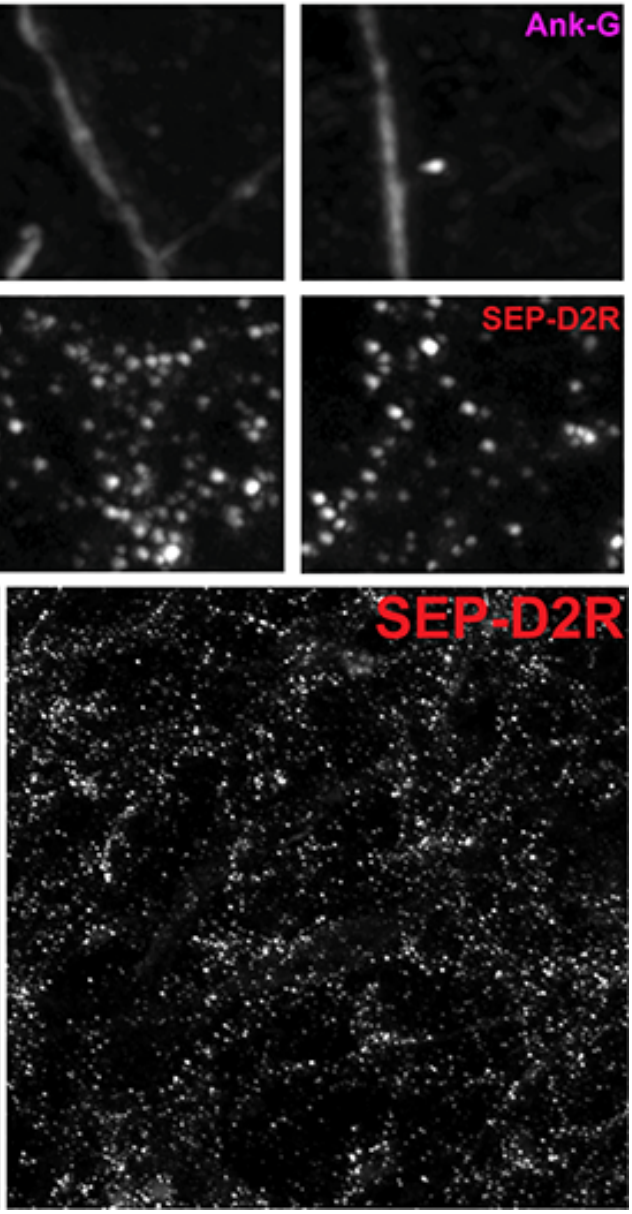

Figure 9

Immunofluorescent labeling of SEP-D2R in the AIS. a. Sub-diffraction limited (Airyscan) image displaying the axon initial segments of $\mathrm{TH}(+)$ dopamine processes (green) as marked by Ank-G localization 
(magenta). SEP-D2Rs are present at the membrane of both processes as red puncta. Scale bar: $10 \mu \mathrm{m} . \mathrm{b}$. Individual channels of merged image displayed in panel a. c. Specified insets from panel a at 2.2x zoom. Both inset panels correspond to regions of AIS profiles where SEP-D2Rs are enriched. Scale bar $10 \mu \mathrm{m}$
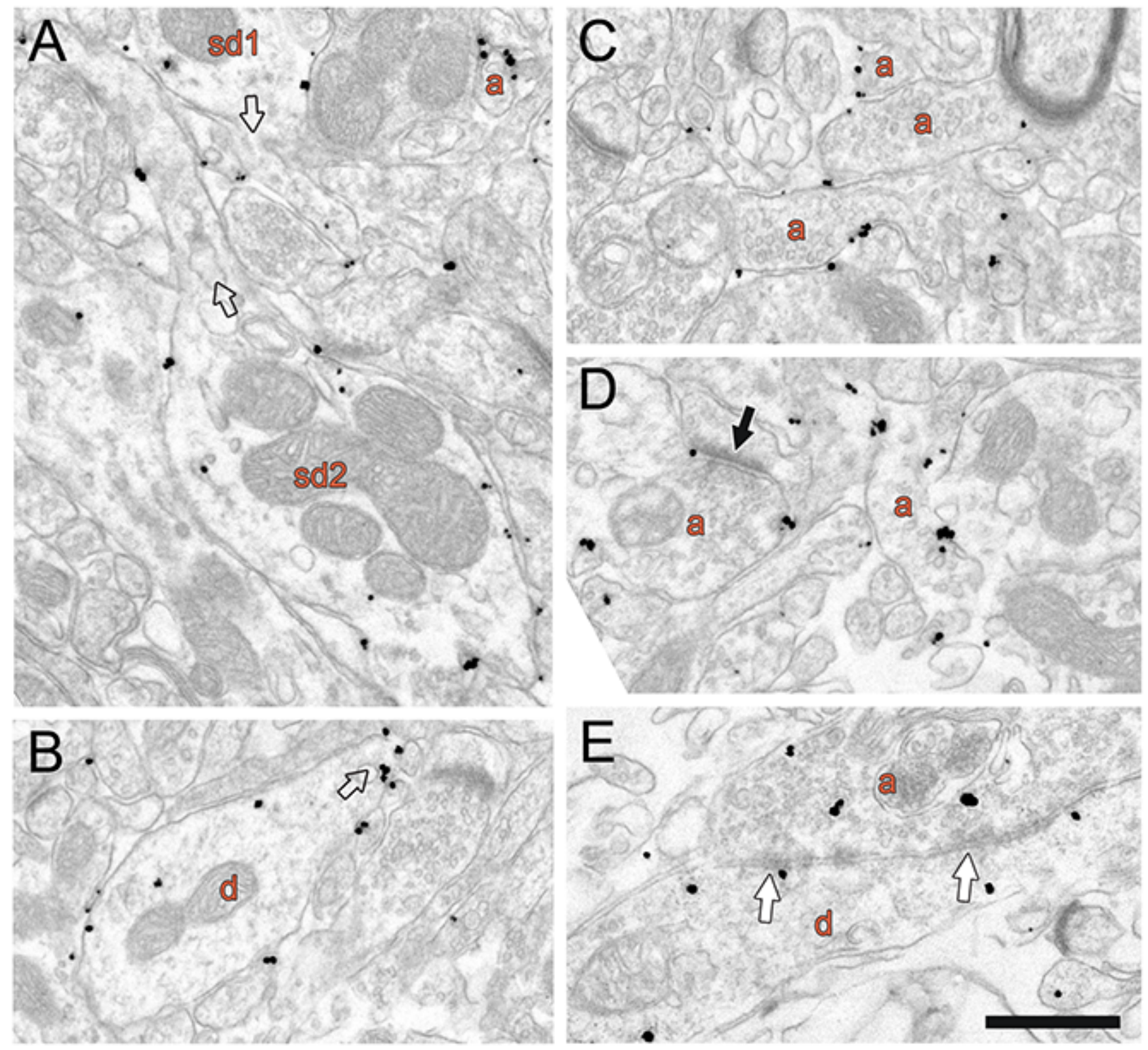

\section{Figure 10}

Electron micrographs of the dorsolateral striatum showing immunogold-silver labeling for SEP-D2R. a. Two spiny dendrites (sd1 and sd2) contain SEP-D2R immunogold mainly present on the membrane of both the dendrites and the necks of their spines (transparent arrows). b. A dendritic profile (d) exhibits predominantly membrane-associated SEP-D2R, with a collection of immunogold found on or near the membrane of what may be the proximal neck of a spine (transparent arrow). c-e. SEP-D2R immunogold is observed mainly on the membranes of axon terminals (a) identified by concentrations of small clear synaptic vesicles. Single-section images show that many of these axon terminals do not form synapses 
in single sections (panels $\mathrm{c}$ and d), although some terminals do form either asymmetric (black arrow in panel d) or symmetric synapses (white arrows in panel e) with nearby dendrites and spines. Scale bar 0.6 $\mu \mathrm{m}$

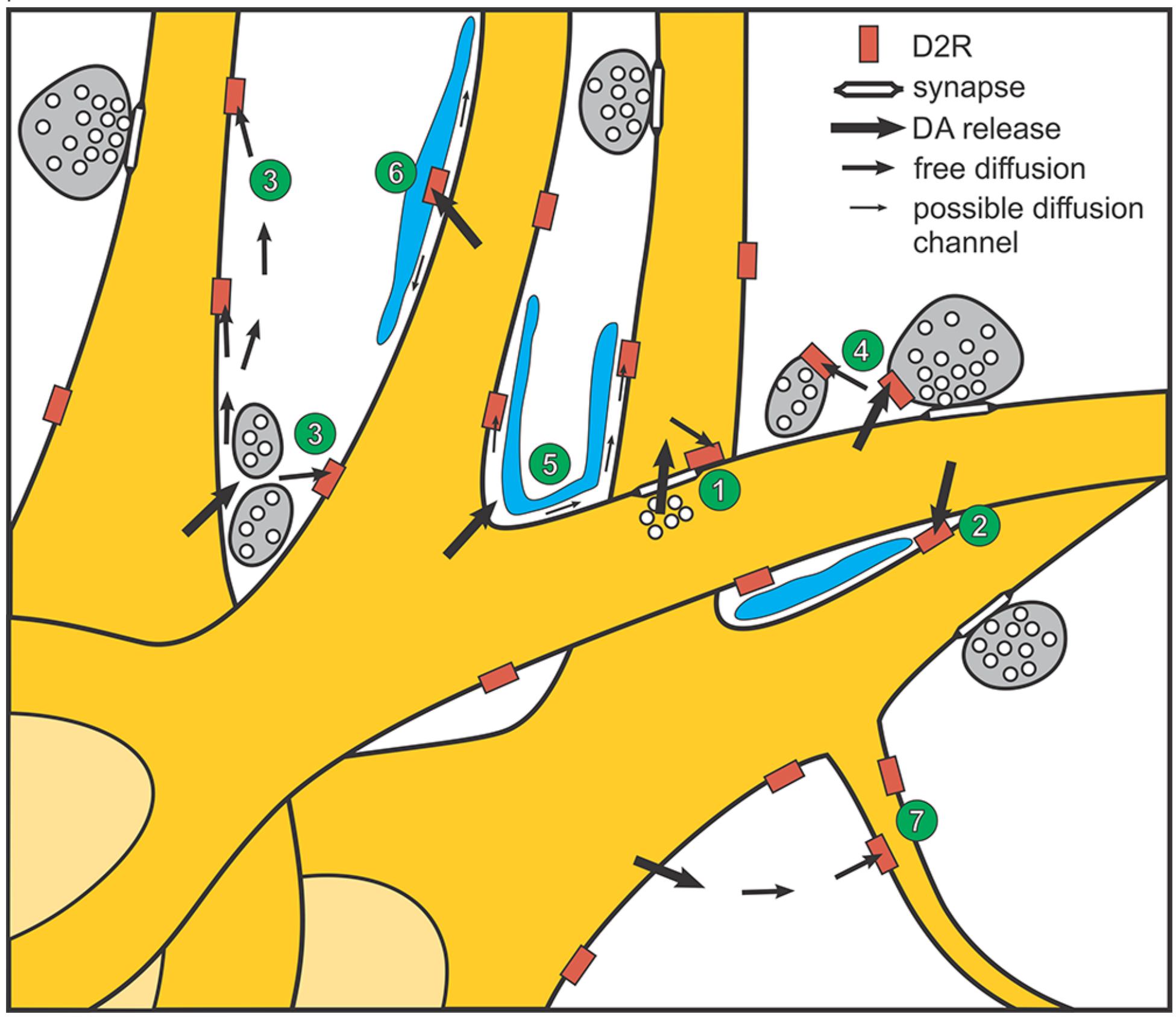

Figure 11

Schematic drawing summarizing the outcomes of the present investigation localizing D2Rs in the SEPD2R mouse SNc and illustrating hypothetical dopamine diffusion. Given the rare detection of dendrodendritic synapses between dopamine neurons (1), most intercellular communication probably involves non-synaptic mechanisms following somatodendritic dopamine release from sites yet to be identified. Relatively rapid transmission is suggested by the modest number of D2Rs found at dendro-dendritic appositions (2). Communication involving short- and long-range diffusion (3) is implied by the more frequent membrane D2Rs observed adjacent to non-dendritic structures. Extracellular diffusion is also 
likely to govern dopamine access to presynaptic D2Rs expressed on axon varicosities (4). The common finding of membrane D2Rs apposed to astrocytes suggests the interesting prospect that dopamine might reach these receptors via diffusion in an extracellular channel formed between the astrocytic and dendritic membranes (5). The fact that some astrocytes themselves express D2Rs suggests that dopamine might be able to control the parameters of diffusion in this channel (6). Finally, the novel finding that D2Rs are expressed along the membrane of the AIS of SNc dopamine cells (7), indicates the possibility that autoreceptors can directly regulate firing rate at this site. Each of these observations is discussed further in the text.

\section{Supplementary Files}

This is a list of supplementary files associated with this preprint. Click to download.

- TablesforSEPD2REMPaper.docx 